\title{
Effect of Continuous and Pulsed Current on the Metallurgical and Mechanical Properties of Gas Tungsten Arc Welded AISI 4340 Aeronautical and AISI 304 L Austenitic Stainless Steel Dissimilar Joints
}

\author{
Moganraj Arivarasu ${ }^{a}$, Devendranath Ramkumar Kasinath ${ }^{a}$, Arivazhagan Natarajan $^{a *}$ \\ ${ }^{a}$ School of Mechanical and Building Sciences, VIT University, Vellore 632 014, India
}

Received: February 05, 2014; Revised: January 26, 2015

\begin{abstract}
In this research work, the weldability of low alloyed AISI 4340 aeronautical steel and AISI 304L austenitic stainless steel joined by continuous current (CC) and pulsed current (PC) gas tungsten arc welding (GTAW) techniques, using ER309L and ERNiCr-3 filler metals was investigated. The main focus of the study involves the investigation on the effect of continuous and pulsed current mode of GTA welding process on the metallurgical and mechanical properties of these dissimilar weldments. Microstructure studies revealed the formation of different zones across the weldments, vis-à-vis martensite at the HAZ of AISI 4340, vermicular $\delta$ - ferrite /ferrite stringers at the HAZ of AISI 304L, pearlite colonies at the parent metal of AISI 4340 and equi-axed cellular and/or columnar dendrites at the weld zone. Tensile results showed that current pulsing accrued better tensile properties. The structure - property relationships of these weldments were established based on the current modes employed by utilizing combined techniques of optical microscopy, scanning electron microscopy (SEM) and energy dispersive spectroscopy (EDS).
\end{abstract}

Keywords: aeronautical steel, AISI 4340, austenitic stainless steel, AISI 304L, dissimilar metal welding, continuous current gas tungsten arc welding, pulsed current gas tungsten arc welding

\section{Introduction}

In industrial practice, it is beneficial to join dissimilar materials due to the effective and economical utilization of the special properties of each material. However, welding of dissimilar metals is a cumbersome and challenging task compared to welding of similar metals. This is due to the differences existing in the chemical composition, coefficients of thermal expansion and thermal conductivity of the base metals to be welded. These differences could severely affect the mechanical and metallurgical properties of weldments. Dissimilar metal welding (DMW) is widely used in power plants, chemical and petrochemical industries, as well as for nuclear and marine applications, due to the accrued demand from the design and economic point of view. These joints are designed to meet much severe service conditions requiring oxidation resistance and high temperature mechanical properties.

Low alloy steel, AISI 4340 (aeronautical steel) has unique applications in the aerospace sector, and is specifically designed for solid fuelled rocket motor cases ${ }^{1,2}$. This alloy offers better strength as compared to other grades. Similarly, austenitic stainless steels have a wide range of engineering applications owing to their strength and excellent corrosion resistance ${ }^{3,4}$.

Sheila et al. $^{5}$ reported the use of AISI 4340 and 300M steels in the aerospace industry. Roshanghias et al. ${ }^{6}$ studied gas tungsten arc welding characteristics of $35 \mathrm{NiCrMoV} 123$ ultra high strength steel, showing that a post welding heat

*e-mail: narivazhagan@vit.ac.in treatment at $310{ }^{\circ} \mathrm{C}$ produces a convenient impact resistant structure, composed of lower bainite.

Hasçalik et al. ${ }^{7}$ reported that bimetallic combinations of austenitic stainless steels and AISI 4340 steels are widely used in engineering applications for the fabrication of structural components. These combinations were designed to meet the service requirements in terms of strength and corrosion resistance. The authors further reported that the development of reliable joints between AISI 4340 and austenitic stainless steel has unlimited applications.

Dissimilar welds of low alloy steel (AISI 4340) and austenitic stainless steel (AISI 304) are designed to evaluate the metallurgical and mechanical properties of the dissimilar weldments keeping in view their proposed usage in energy conversion systems/power generation industry ${ }^{8}$. In a nuclear water reactor, dissimilar weldments are employed to connect the low alloy steel reactor pressure vessel and stainless steel pipe systems. Bhaduri et al. ${ }^{9}$ reported that the use of low-alloy steels and austenitic stainless steels would be a better alternative for primary boilers and heat exchangers operating at high temperatures with corrosive environmental conditions.

In general, the individual combinations of austenitic stainless steels/low alloy steel are easily weldable. However, the selection of process parameters and an appropriate filler wire for joining these dissimilar metals is really cumbersome, as it has a great impact in altering the structure as well as property in the weld zones. Improper selection of filler metals may contribute for the problems, which 
include hot cracking, solidification cracking and ductility dip cracking etc. which could affect the quality of welds. It was reported by several researchers ${ }^{10-12}$ that problems such as micro-segregation, secondary phase formation and dilution cracks could be attributed to the improper selection of the welding process and filler material. It was also recommended to employ minimum preheating on the alloyed steels to prevent cracking. Another major concern associated with dissimilar metal welding is the elemental migration. Specifically, the carbon migration between the weld and base metals is one of the major concerns, which leads to a carbon denuded soft zone. A carbon denuded soft zone was observed in the lower-chromium base metal adjacent to the weld interface while welding Cr-Mo weldments. The carbon migration is primarily driven by elemental differences, especially in chromium content, between the weld metal and base metal. It was also reported that nickel based fillers cannot completely prohibit the formation of soft zone, but can greatly decrease the growth rate of the soft zone ${ }^{13}$.

Arivazhagan et al. ${ }^{8}$ investigated the mechanical properties of the dissimilar weldments of AISI 4140 and AISI 304 obtained by gas tungsten arc, electron beam and friction welding. The authors reported that the segregation of $\mathrm{C}, \mathrm{Fe}$ and $\mathrm{Cr}$ in the weld interface influences the mechanical properties of the weldment.

Also, the combined carbon and alloy contents of the Heat Treatable Low Alloy (HTLA) steels like AISI 4340 are sufficient to promote the formation of martensite-austenite, when cooled rapidly to below the appropriate transformation temperature. The carbon content is sufficiently high to form hard martensite, which may be brittle. During welding, a portion of the heat-affected zone (HAZ) would transform to austenite. If the weld metal and the austenitic heat-affected zone are cooled too fast, they would be transforming to martensite or a combination of martensite and bainite ${ }^{14}$.

Özdemira et al. ${ }^{15}$ reported that the similar and dissimilar joints involving austenitic steels are susceptible to unexpected phase propagation. Due to this, unexpected or a series of negative metallurgical changes, such as formation of sigma phase, occurs which in turn leads to grain boundary corrosion at the weld interface. Therefore, higher welding speeds are necessary to avoid such effects.

The use of pulsed current has been explored in the past few years for obtaining grain refinement at the fusion zone. Sundaresan et al. ${ }^{16}$ have employed current pulsing on various metals to obtain grain refinement in weld fusion zones and reported the accrued benefits in weld mechanical properties. Mohandas et al. ${ }^{17}$ compared the effect of Continuous Current (CC) and Pulsed Current Gas Tungsten Arc (PCGTA) welding techniques on the metallurgical and mechanical properties of ultra-high strength steel. The authors reported that the strength and ductility of the PCGTA welds was found to be greater than CCGTA welds. It was also concluded that PCGTA welding resulted in finer grain size, and smaller martensitic platelets coupled with less tendency of segregation.

As evident from the literature, although there is a unique demand for these bimetallic combinations in the diversified fields of engineering, Very skimpy information has been documented in the open literatures hitherto. Hence, this work assumes potential significance in the areas where these combinations are employed.

In this investigation, an attempt has been made to compare the weldability, metallurgical and mechanical properties of AISI 4340 and AISI 304L using Continuous Current (CC) and Pulsed Current Gas Tungsten Arc (PCGTA) welding techniques, employing ER309L and ERNiCr-3 filler metals. Combined techniques of Optical Microscopy (OM), Scanning Electron Microscopy (SEM) and Energy Dispersive Spectroscopy (EDS) analysis were employed to intercept the structure - property relationships of these weldments.

\section{Experimentation}

\subsection{Base metals and welding procedure}

The candidate and filler metals employed in this study were AISI 304L, AISI 4340 and ER309L, ERNiCr-3 respectively, whose chemical composition is represented in Table 1 . The as-received base metals were cut to plates using wire cut Electrical Discharge Machining $(E D M)$ having the dimensions of $150 \times 55 \times 5 \mathrm{~mm}$. Standard $\mathrm{V}$-Butt configurations (single $\mathrm{V}$-groove having a root gap of $2 \mathrm{~mm}$, size land of $1 \mathrm{~mm}$ and included angle of $70^{\circ}$ ) were employed on these plates. These plates were butt welded by CCGTA and PCGTA welding techniques, using inverter based Kemppi Master TIG MLS welding machine. The process parameters were based on the works carried out by other researchers ${ }^{18-20}$ and also established using bead on plate welding and are given in Table 2. Selective pre-heating is carried out for AISI 4340 to $120^{\circ} \mathrm{C}$, while the AISI 304L side was covered with glass wool. The weldments were characterized for any defects using gamma ray radiography technique. Ensuing to the results, the welded samples were cut into different coupons for further analysis.

\subsection{Macro and microstructure studies}

Macro and microstructure studies were carried out on the cross section coupons named as "composite region" whose dimensions are $30 \times 15 \times 5 \mathrm{~mm}$, which covers all the zones (parent metals - heat affected zones - weld) of the weldments.

Table 1. Chemical Composition of the base and filler metals.

\begin{tabular}{|c|c|c|c|c|c|c|c|c|c|c|c|}
\hline \multirow{2}{*}{$\begin{array}{c}\text { Base/Filler } \\
\text { Metal }\end{array}$} & \multicolumn{11}{|c|}{ Chemical Composition (\% by Weight) } \\
\hline & $\mathbf{C}$ & Si & Mn & $\mathbf{C r}$ & $\mathbf{N i}$ & $\mathrm{Nb}$ & Mo & $\mathbf{F e}$ & $\mathbf{C r} \mathbf{r e q}$ & $\mathrm{Ni}_{\mathrm{eq}}$ & $\mathrm{Cr}_{\mathrm{eq}} / \mathrm{Ni} \mathrm{eq}_{\mathrm{eq}}$ \\
\hline AISI 4340 & 0.31 & 0.23 & 0.64 & 0.98 & 1.34 & - & 0.23 & Bal. & 1.56 & 10.96 & 0.14 \\
\hline AISI 304L & 0.037 & 0.46 & 0.95 & 19.14 & 8.35 & - & 0.17 & Bal. & 20 & 9.93 & 2.01 \\
\hline ERNiCr-3 & 0.02 & 0.1 & 3.1 & 20.5 & Bal. & 2.6 & - & 1.0 & 21.95 & 75.83 & 0.29 \\
\hline ER309L & 0.02 & 0.5 & 1.7 & 24.0 & 13.2 & - & - & Bal. & 24.76 & 13.39 & 1.85 \\
\hline
\end{tabular}

$\mathrm{Ni}_{\text {eq }}=\% \mathrm{Ni}+(\% \mathrm{C} \times 30)+(\% \mathrm{Mn} \times 0.5) ; \mathrm{Cr}_{\text {eq }}=\% \mathrm{Cr}+\% \mathrm{Mo}+(\% \mathrm{Si} \times 1.5)+(\% \mathrm{Nb} \times 0.5)$. 
Table 2. Process Parameters employed in the study.

\begin{tabular}{|c|c|c|c|c|c|c|c|c|c|c|c|}
\hline Process & Filler & $\begin{array}{c}\text { Filler } \\
\text { rod Dia. } \\
(\mathrm{mm})\end{array}$ & $\begin{array}{c}\text { Voltage } \\
\text { (V) }\end{array}$ & $\begin{array}{c}\text { Current } \\
\text { (A) }\end{array}$ & $\begin{array}{c}\text { Base } \\
\text { Current } \\
\mathbf{I}_{\text {base }}(\mathbf{A})\end{array}$ & $\begin{array}{c}\text { Peak } \\
\text { Current } \\
I_{\text {peak }}(\mathrm{A})\end{array}$ & $\begin{array}{c}\text { Pulse on } \\
\text { Time }\end{array}$ & $\begin{array}{c}\text { Frequency } \\
\text { HZ }\end{array}$ & $\begin{array}{c}\text { Welding } \\
\text { speed } \\
\mathbf{V} \\
\mathrm{mm} / \mathrm{min}\end{array}$ & $\begin{array}{l}\text { Gas } \\
\text { Flow } \\
\text { Rate I/ } \\
\text { min }\end{array}$ & $\begin{array}{c}\text { Heat } \\
\text { Input } \\
\text { kJ/mm }\end{array}$ \\
\hline GTAW & ER 309L & 2.4 & $\begin{array}{c}11.6 \\
- \\
14.9\end{array}$ & $\begin{array}{c}152 \\
- \\
170\end{array}$ & - & - & & - & 120 & 13 & $\begin{array}{c}0.5296 \\
- \\
0.7599\end{array}$ \\
\hline PCGTAW & ER 309L & 2.4 & $\begin{array}{c}10.8 \\
- \\
14.9\end{array}$ & - & $\begin{array}{l}80 \\
- \\
85\end{array}$ & $\begin{array}{c}160 \\
- \\
170\end{array}$ & $50 \%$ & 6 & 120 & 13 & $\begin{array}{c}0.4536 \\
-0.6693\end{array}$ \\
\hline GTAW & ERNiCr-3 & 2.4 & $\begin{array}{c}12.3 \\
- \\
15.2\end{array}$ & $\begin{array}{c}152 \\
- \\
170\end{array}$ & - & - & & - & 120 & 13 & $\begin{array}{c}0.560 \\
- \\
0.7752\end{array}$ \\
\hline PCGTAW & $\begin{array}{c}\text { ER } \\
\text { NiCr-3 }\end{array}$ & 2.4 & $\begin{array}{c}10.8 \\
- \\
14.9\end{array}$ & - & $\begin{array}{c}76 \\
- \\
85\end{array}$ & $\begin{array}{c}152 \\
- \\
170\end{array}$ & $50 \%$ & 6 & 120 & 13 & $\begin{array}{c}0.4998 \\
- \\
0.6649\end{array}$ \\
\hline
\end{tabular}

These composite regions were polished using the emery sheets of 400 to 2000 grit sizes, followed by disc polishing using alumina solution, so as to obtain mirror like finish of accuracy $1 \mu$ on the coupons. Standard metallographic procedures were employed to examine the microstructure of the weldments using optical microscopy and scanning electron microscopy techniques. $\operatorname{Nital}\left(2 \% \mathrm{HNO}_{3}\right)$ was used as etchant for examining the microstructure at the weld -HAZ - parent metal side of AISI 4340, whereas a solution containing $15 \mathrm{ml} \mathrm{HCl}+10 \mathrm{ml} \mathrm{HNO}_{3}+10 \mathrm{ml} \mathrm{CH}_{3} \mathrm{COOH}$ was employed to reveal the microstructure at the weld region of ER309L weldments and the parent metal side of AISI 304L. In addition, electrolytic etching (10 g Oxalic acid $+100 \mathrm{ml}$ distilled water $-6 \mathrm{~V}$ DC supply; $7 \mathrm{~s}$ was used to examine the microstructure at the ERNiCr-3 welds.

\subsection{SEM/EDS analysis}

SEM/EDS analysis was performed on the various zones of the weldments to determine the presence of phases, as well as various elements across the weld profile to assess the structure - property correlations.

\subsection{Mechanical characterization of the weldments}

Mechanical characterization of the weldments was established by conducting the hardness and tensile tests. Hardness measurement was carried out on the composite region of the weldments using Vicker's micro-hardness tester with a load of $500 \mathrm{gf}$ for a dwell time of $10 \mathrm{~s}$, at regular intervals of $0.25 \mathrm{~mm}$. Tensile studies were performed on the weldments prepared as per the ASTM E8 standards ${ }^{21}$ with a cross-head velocity of $2 \mathrm{~mm} / \mathrm{min}$ at room temperature. Three trials were conducted on the weldments to check the reproducibility of the results. Furthermore, the fractured samples were characterized for SEM analysis to determine the mode of fracture.

\section{Results}

\subsection{Macrograph examination of the weldments}

It is evident from the visual examination (Figure 1) that the sound weld joints of AISI 304L and AISI 4340 shall be achieved on employing both CC and PCGTA welding modes. No physical surface defects like arc strike, cracks and undercut were observed in any of the weldments. Further, Non Destructive Testing (NDT) on the dissimilar joints substantiated that the weldments were free from sub-surface weld defects such as inclusions, porosity and lack of fusion etc. Macrostructure examination (Figure 2) clearly construed that proper fusion had occurred without any macro scale deficiencies on the dissimilar weldments obtained from CCGTA and PCGTA welding techniques employing ER309L and ERNiCr-3.

A simple interpretation through macrostructure examination had given a clear view that the width of the weld region of CCGTA weldments was found to be broader as compared to the PCGTA weldments. In specific, the width of weld bead is found to be $5.31 \mathrm{~mm}$ and $2.53 \mathrm{~mm}$ for the weldments employing ER309L filler in continuous mode and pulsed mode respectively. For the weldments employing ERNiCr-3 filler, the width was found to be $3.89 \mathrm{~mm}$ in the continuous mode and $2.18 \mathrm{~mm}$ in the pulsed mode.

\subsection{Micro-structure examination of the weldments}

Microstructure examination (Figures 3-6) clearly envisaged the formation of martensite at the HAZ of AISI 4340 and Migrated Grain Boundaries (MGBs) on the weld zones for all the weldments. Formation of delta ferrite stringers in the austenitic grains was observed at the HAZ of the AISI 304L for all the weldments, which are in agreement with Naffakh et al. ${ }^{22}$

\subsubsection{CCGTA welds using ER309L filler wire}

Micrographs clearly showed the prominent formation of martensite at the HAZ of AISI 4340 side (Figure 3a). Grain coarsening effect and the presence of clusters of $\delta$ - ferrite at the HAZ of AISI 304L side was observed (Figure 3b). The weld zone has been predominated by the presence of vermicular $\delta$ - ferrite in the root region of the weld zone (Figure 3c) and MGBs were observed adjacent to the cap region (Figure $3 b$ ). 


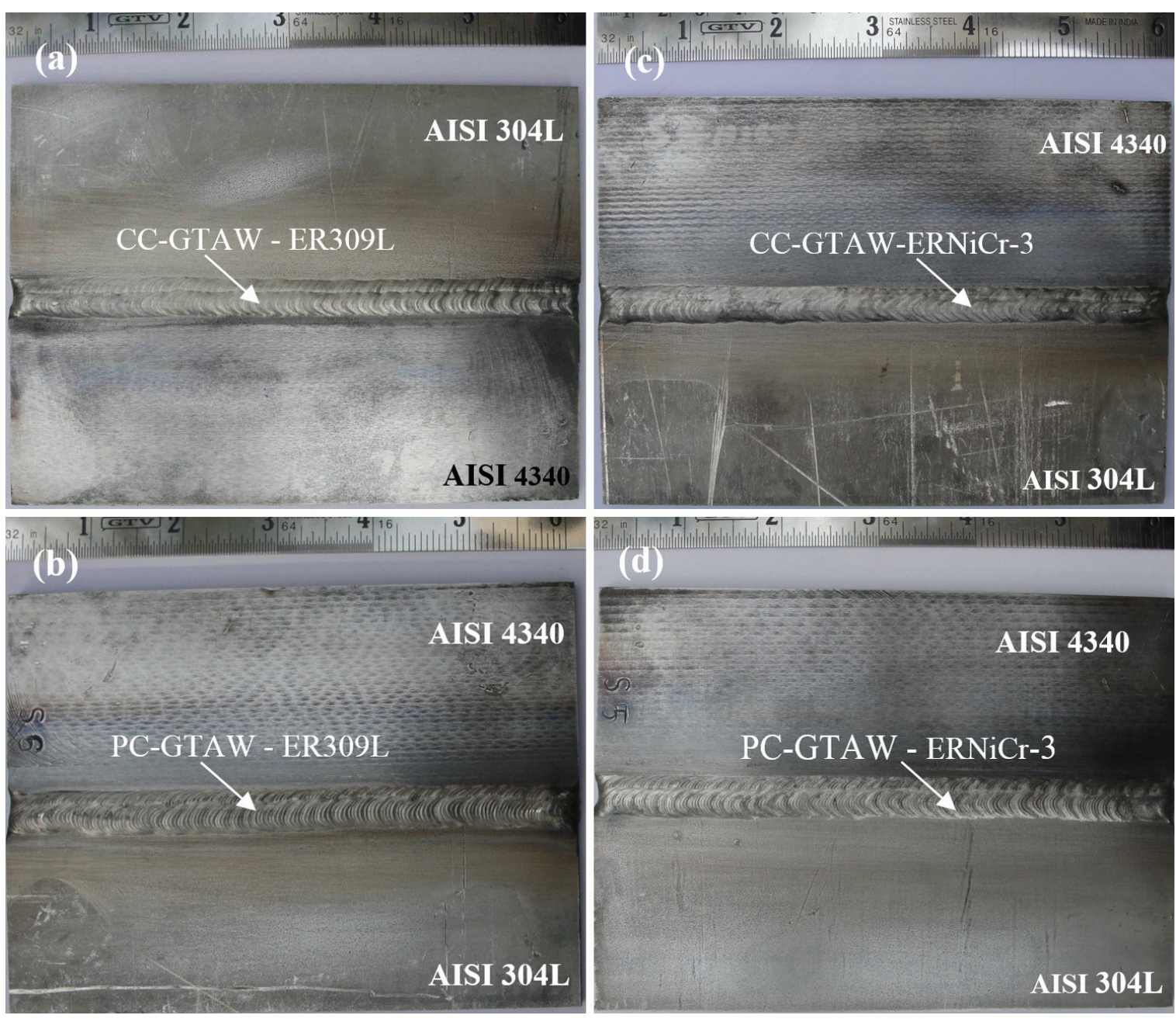

Figure 1. Photographs of the dissimilar weldments of AISI 4340 and AISI 304L employing (a) CCGTAW-ER309L (b) PCGTAW-ER309L (c) CCGTAW-ERNiCr-3 (d) PCGTAW-ERNiCr-3.
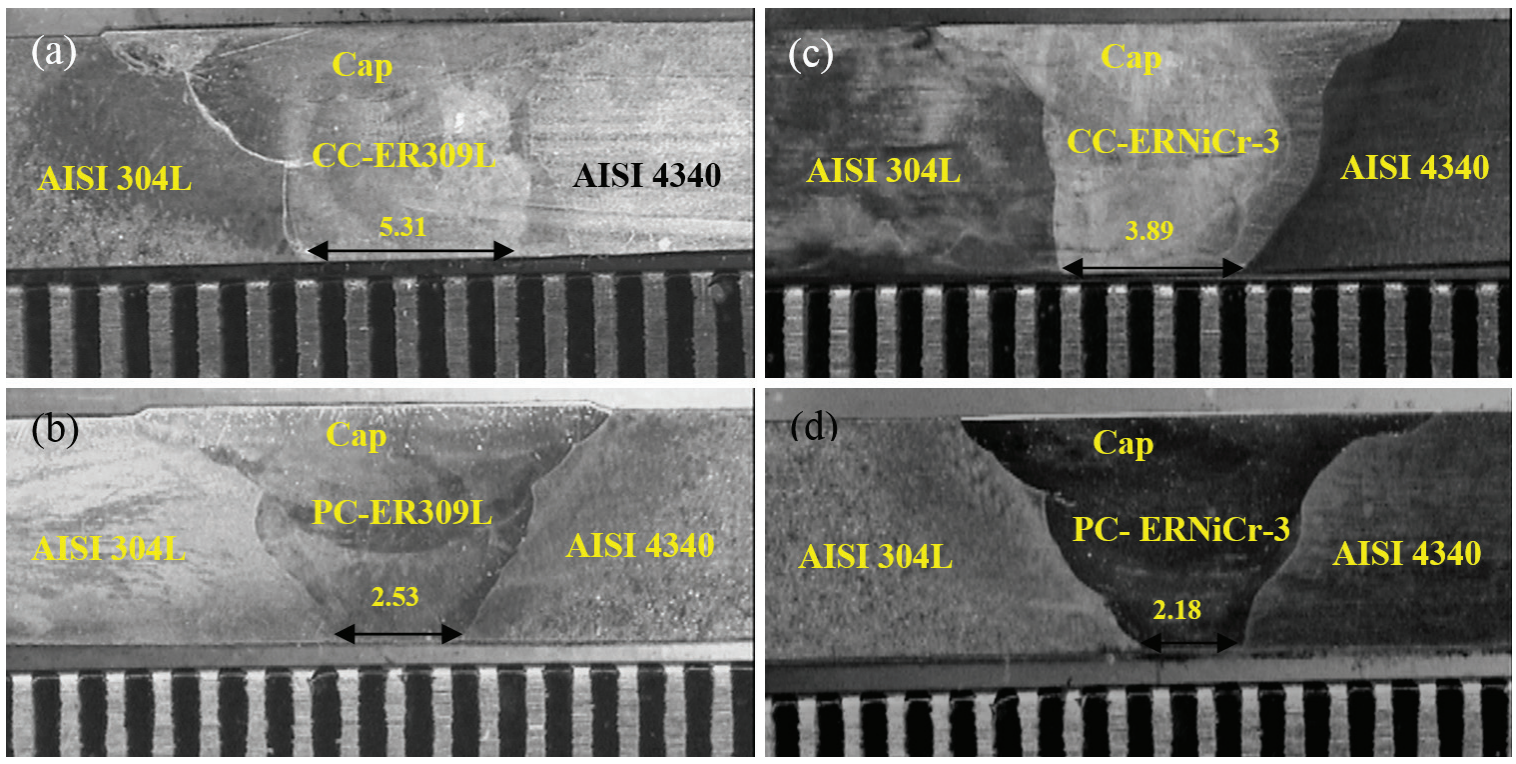

Figure 2. Macrostructures of the dissimilar weldments of AISI 4340 and AISI 304L employing (a) CCGTAW-ER309L (b) PCGTAW-ER309L (c) CCGTAW-ERNiCr-3 (d) PCGTAW-ERNiCr-3. 

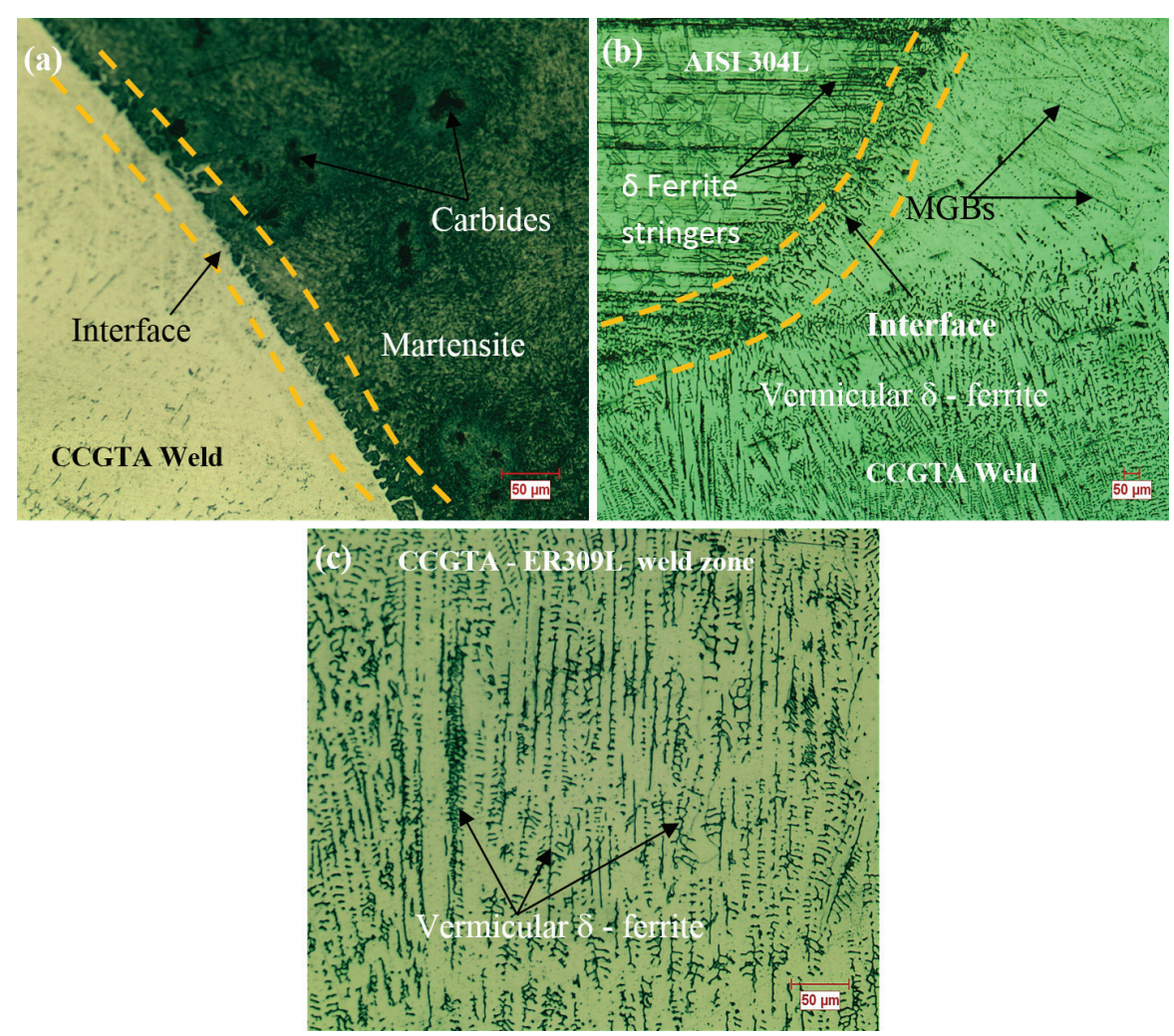

Figure 3. Microstructure of CCGTAW AISI 4340 and AISI304L welded with ER309L Filler Wire a) Interface between weld and AISI 4340 b) Interface between weld and AISI 304L c) CCGTAW ER309L weld zone.
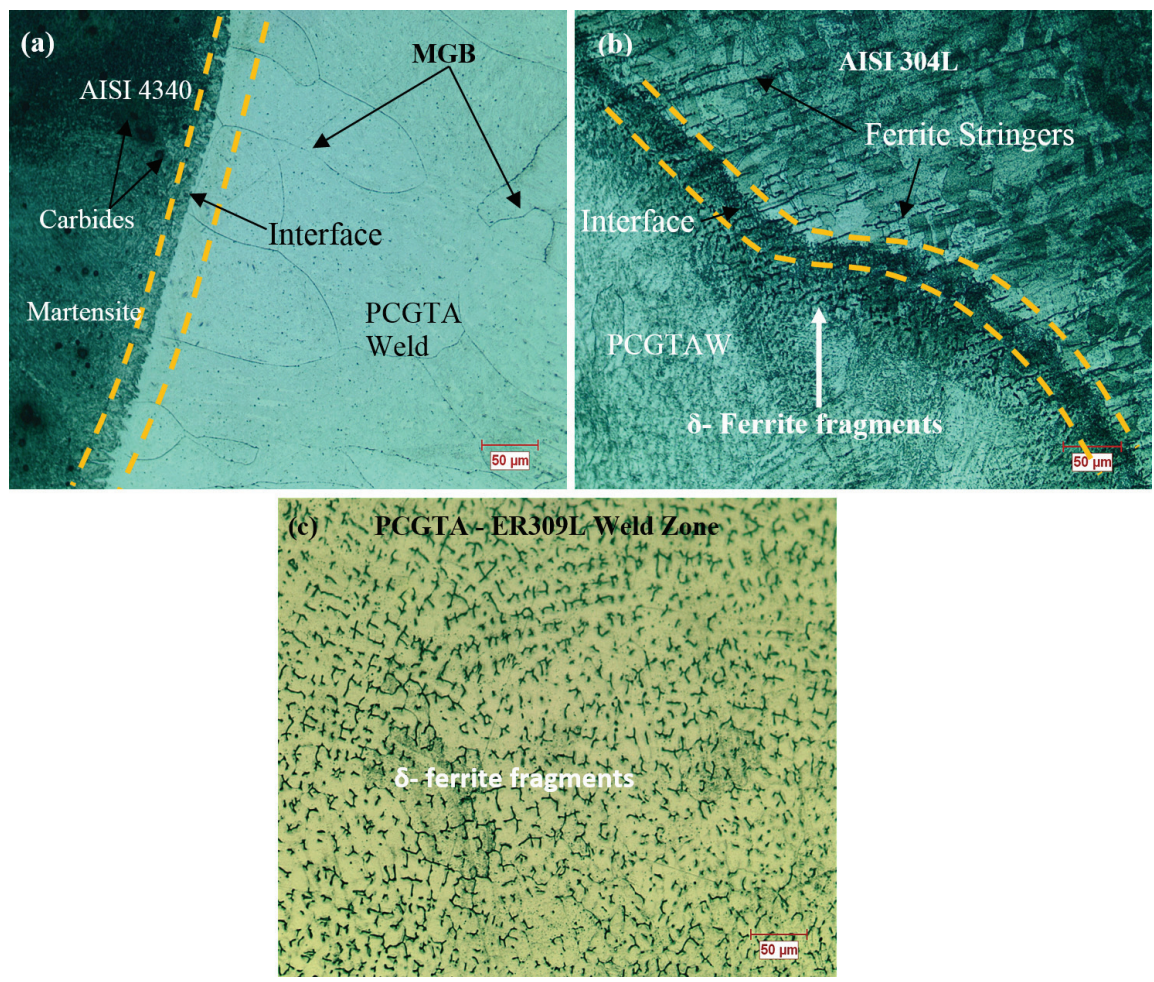

Figure 4. Microstructure of PC-GTAW AISI 4340 and AISI 304L welded with ER309L Filler Wire a) Interface between weld and AISI 4340 b) Interface between weld and AISI 304L c) PCGTAW ER309L weld zone. 

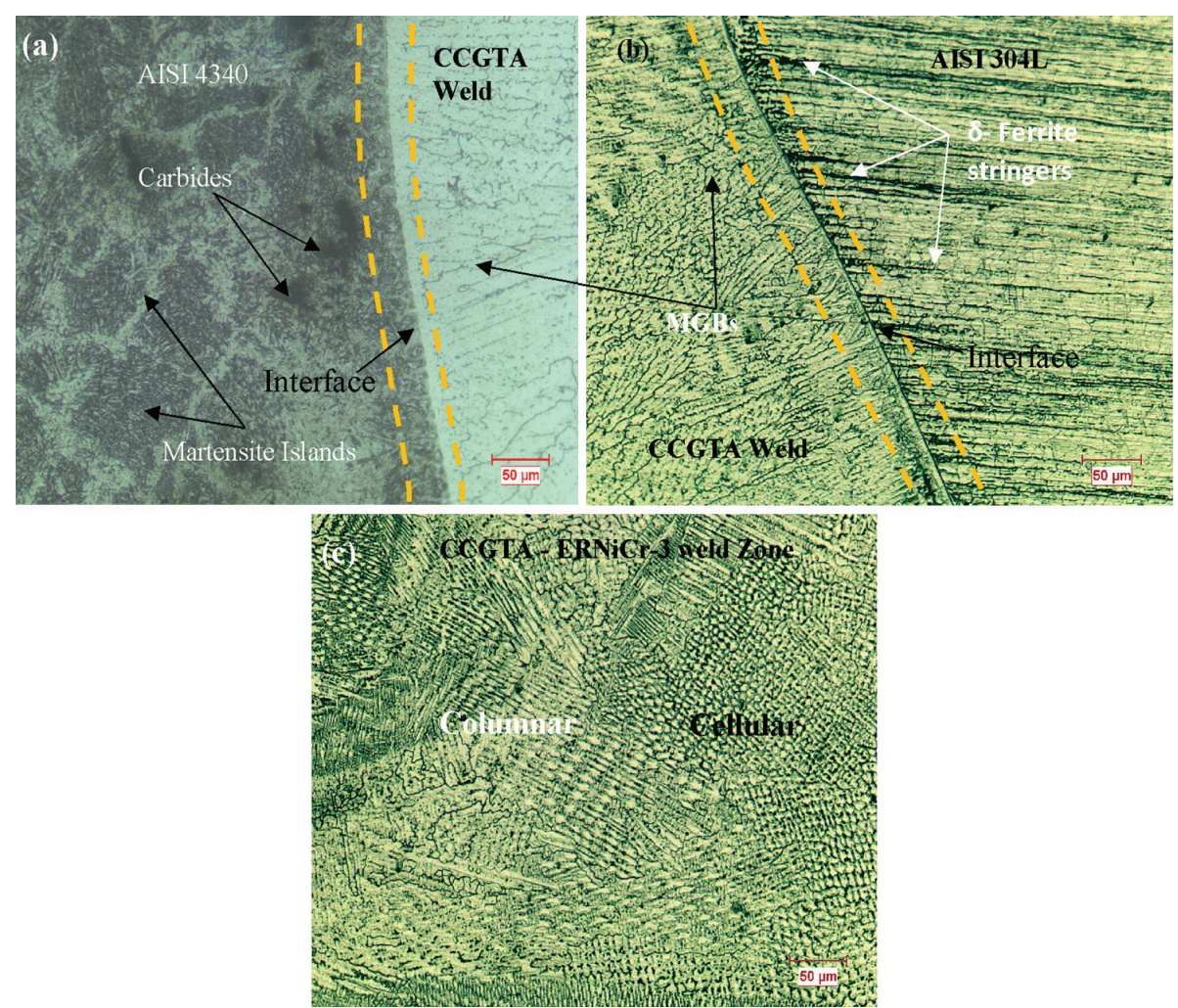

Figure 5. Microstructure of CC-GTAW AISI 4340 and AISI304L welded with ERNiCr-3 Filler Wire a) Interface between weld and AISI 4340 b) Interface between weld and AISI 304L c) CCGTAW-ERNiCr-3 weld Zone.
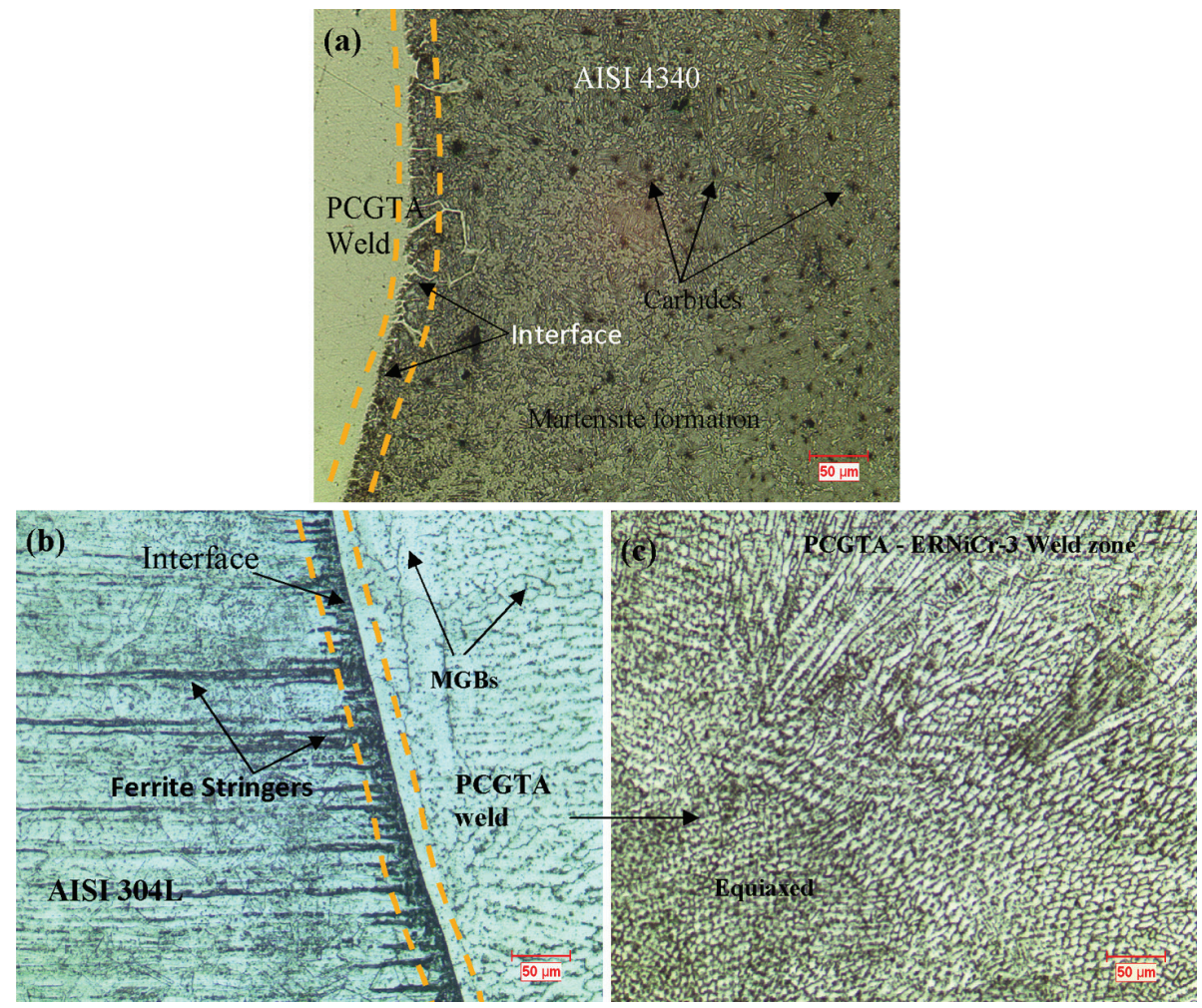

Figure 6. Microstructure of PC-GTAW AISI 4340 and AISI 304L welded with ERNiCr3 Filler Wire a) Interface between weld and AISI 4340 b) Interface between weld and AISI 304L c) PCGTAW-ERNiCr-3 weld Zone. 


\subsubsection{PCGTA welds using ER309L filler wire}

It was evident from the micrographs that the PCGTA welds had produced fine martensite structure at the HAZ of AISI 4340 and the coarse grains at the HAZ of AISI 304L side (Figures $4 a, b$ ). Further the weld zone contains well defined MGBs (Figure 4a) and $\delta$ - ferrite fragmentation (Figure 4c).

\subsubsection{CCGTA welds using ERNiCr-3 filler wire}

Formation of prominent martensitic islands at the HAZ of AISI 4340 side and lesser amounts of $\delta$-ferrite stringers with well-defined weld interface were perceived at the HAZ of AISI 304L (Figures 5a, b). The weld zone was found to be fully austenitic with the presence of columnar dendrites with few cellular structures at the weld centre. Also, the presence of MGBs adjacent to the weld interface was witnessed (Figures 5b, c).

\subsubsection{PCGTA welds using ERNiCr-3 filler wire}

The micrographs had clearly discerned the formation of fine martensitic structure with the dispersed dark phases at the HAZ of AISI 4340 and meagre amounts of $\delta$-ferrite stringers at the HAZ of AISI 304L side Figures $6 \mathrm{a}$, b. Further, the weld zone had clearly shown the presence of cellular dendrites and equi-axed grain growth with the presence of MGBs (Figures 6b, c).

\subsection{SEM/EDS analysis on the as-welded samples}

SEM/EDS analysis was carried out on the composite region of the as-welded samples, which is represented in Figures 7-10. The property of weldments is generally influenced by the various alloying elements such as $\mathrm{Cr}$, $\mathrm{Ni}$ and $\mathrm{Fe}$ and hence, these elements are mainly focussed in the EDS analysis. As discussed earlier, MGBs are quite prominent in the fully austenitic, austenitic-ferritic or ferritic - austenitic welds. The EDS analysis inferred the same by showing considerable amounts of $\mathrm{Ni}$ at the weld zone for all the weldments. Further, the values of $\mathrm{Ni}_{\text {eq }}$ and $\mathrm{Cr}_{\text {eq }}$ at the weld zones were determined using the Schaeffler diagram Figure 11 which also confirmed the same.

\subsubsection{CCGTA welds using ER309L filler}

EDS results (Figure 7b) had shown that the Fe content at the weld zone (Z1) near the fusion line of AISI 304L was found to be $70.16 \%$ as compared $60.58 \%$ in ER309L filler metal. This clearly indicates that there was a migration of the Fe from AISI 304L. The Cr constituent present in the weld zone and the parent metal was found to be $18.39 \%$ and $19.14 \%$ respectively. Hence, there is a possible chance of less movement of $\mathrm{Cr}$ from weld zone to the AISI $304 \mathrm{~L}$ side. Another constituent Ni, which was observed to be $7.76 \%$ at the weld zone and $8.85 \%$ in the base metal also had lesser migration.

On the other hand, near the weld Zone (Z2) of AISI 4340 side, Fe had migrated from the AISI 4340 base metal to the ER309L weld. The nominal composition of Fe in the ER309L filler wire is $60.58 \%$ by weight; however the EDS analysis had shown that the Fe content is $80.31 \%$ in the weld interface. This shows clearly that there was an enrichment of Fe in the weld interface of AISI 4340 side. Similarly, the $\mathrm{Cr}$ and $\mathrm{Ni}$ content in the filler wire is $24 \%$ and $13.2 \%$. From the EDS analysis, it was noticed that $\mathrm{Cr}$ and $\mathrm{Ni}$ have been depleted at the weld interface, as the percentage of these elements was found to be $10.50 \%, 5.31 \%$ respectively.

\subsubsection{PCGTA welds using ER309L filler}

From the EDS results, (Figure 8) it was observed that the constituent $\mathrm{Fe}$ in the weld zone (Z2) of AISI 4340 side was $73.48 \%$, which was quite higher compared to the ER309L filler wire $(60.58 \%) \mathrm{Fe}$. However, the Fe migration was found to be lesser in case of PCGTA compared to GTAW. The $\mathrm{Cr}$, Ni content was found to be $13.29 \%, 6.61 \%$ at the weld zone which is prominently lower compared to these elements present in the filler wire as $24 \%$ and $13.2 \%$ respectively. This also contributed to the depletion of these elements during welding process. Further, it was noticed that the migration of these elements are found to be lesser compared to CCGTA welding process.

\subsubsection{CCGTA welds using ERNiCr-3 filler}

It was observed from the EDS analysis (Figure 9) that the $\mathrm{Cr}$ constituent at the HAZ of AISI 304L and the base metal AISI $304 \mathrm{~L}$ was $22.84 \%, 18.85 \%$ respectively shows enrichment of $\mathrm{Cr}$. Fe content at the weld zone (Z1) adjacent to the AISI $304 \mathrm{~L}$ side was found to be $47.75 \%$. This clearly showed that $\mathrm{Fe}$ had migrated from the AISI 304L to weld side. The amount of $\mathrm{Ni}$ at the weld zone was found to be $30.94 \%$, which clearly showed the migration of $\mathrm{Ni}$ to the AISI 304L side, or might have been depleted during the welding process.

\subsubsection{PCGTA welds using ERNiCr-3 filler}

At the weld zone (Z1) near AISI 304 L side (Figure 10), the constituents $\mathrm{Fe}$, Ni was observed to be $51.12 \%$ and $27.31 \%$ respectively from the EDS analysis. There was not much difference observed in the $\mathrm{Cr}$ constituent. On the other hand, the weld Zone (Z2) near AISI 4340 side, the Fe, $\mathrm{Ni}$ and $\mathrm{Cr}$ constituents were found to be $58 \%, 27.8 \%$ and $12.7 \%$ respectively. It was evident that $\mathrm{Cr}$ and $\mathrm{Ni}$ had been depleted in the weld zone as compared to the filler metal's composition.

\subsection{Micro-hardness}

Micro-hardness test plots for the weldments obtained from the aforementioned fillers and welding techniques are represented in Figures 12a, b. A general observation on the hardness trend was that the average hardness value was found to be greater at the HAZ of AISI 4340 side compared to other zones of the weldments. The hardness values at the HAZ of AISI 304L side had shown little variation compared to its base metal.

\subsubsection{CCGTA weld using ER309L filler wire}

The weld zone showed an average hardness value of 203 HV (Figure 12a), which was lower as compared to the other zones of the weldments. A peak weld hardness of $262 \mathrm{HV}$ was observed near the fusion line of AISI 4340. The hardness trend was fluctuating and the average hardness value of $373 \mathrm{HV}$ was observed at the HAZ of AISI 4340. Dark spots observed at the HAZ of AISI 4340 had shown 
the peak hardness values. The width of the HAZ was found to be $7 \mathrm{~mm}$ from the weld centre.

\subsubsection{PCGTA weld using ER309L filler wire}

The average hardness value at the weld zone (Figure 12a) was found to be $258 \mathrm{HV}$ and a peak hardness value of $424 \mathrm{HV}$ was also obtained near the fusion zone of AISI 4340. On the other hand the peak hardness value of $265 \mathrm{HV}$ was observed at the weld centre. The maximum hardness value at the HAZ of AISI 4340 was found to be $398 \mathrm{HV}$ and the hardness value gradually decreased from the peak values towards base metal. The HAZ was found to be spread till $4.75 \mathrm{~mm}$ from weld centre.

\subsubsection{CCGTA weld using ERNiCr-3 filler wire}

As observed earlier, these weldments also experienced lower hardness value of $194 \mathrm{HV}$ at the weld zone (Figure 12b). Also, a drop in hardness value to $157 \mathrm{HV}$ was divulged near the weld centre. A maximum hardness of $383 \mathrm{HV}$ was observed at the HAZ of AISI 4340 and additionally, a gradual decrease in the hardness values from the peak hardness was noticed. In this case, the width of the HAZ was found to be $6 \mathrm{~mm}$ from the weld centre.

\subsubsection{PCGTA weld using ERNiCr-3 filler wire}

The hardness values in the weld zone (Figure 12b) were almost uniform and an average hardness value of $207 \mathrm{HV}$ was observed. In these weldments, the maximum hardness value was found to be $418 \mathrm{HV}$ at the HAZ of AISI 4340. However the hardness trend was found to be fluctuating at this zone, which had shown peak hardness of $602 \mathrm{HV}$ and a minimum of $316 \mathrm{HV}$. The width of the HAZ in these weldments was found to be $5.5 \mathrm{~mm}$ from the weld centre.

\subsection{Tensile testing}

Tensile test results showed that the weldments had undergone typical ductile mode of fracture irrespective of the welding techniques and filler metals (Figure 13). A fascinating observation was that the failure occurred at the weld zone in all the trials for all the weldments. Also, the tensile test trials provided sound information that the average tensile strength of the PCGTA weldments was found to be better as compared to other weldments. Specifically, the average tensile strength of PCGTA weldments employing ER309L filler was found to be more (602.6 MPa) compared to CCGTAW (562.7 MPa). Similarly, the PCGTA weldments employing ERNiCr-3 filler (665.3 $\mathrm{MPa}$ ) offered better tensile properties compared to CCGTAW employing ERNiCr-3 filler (611.5 MPa).

\subsection{SEM Tensile fractographs}

The SEM fractographs represented in Figure 14a witnessed the formation of fibrous network with few macro voids in tensile fractured ER309L welds fabricated by CCGTA welding process; whereas, the fractographs of ER309L welds obtained from PCGTA welding process
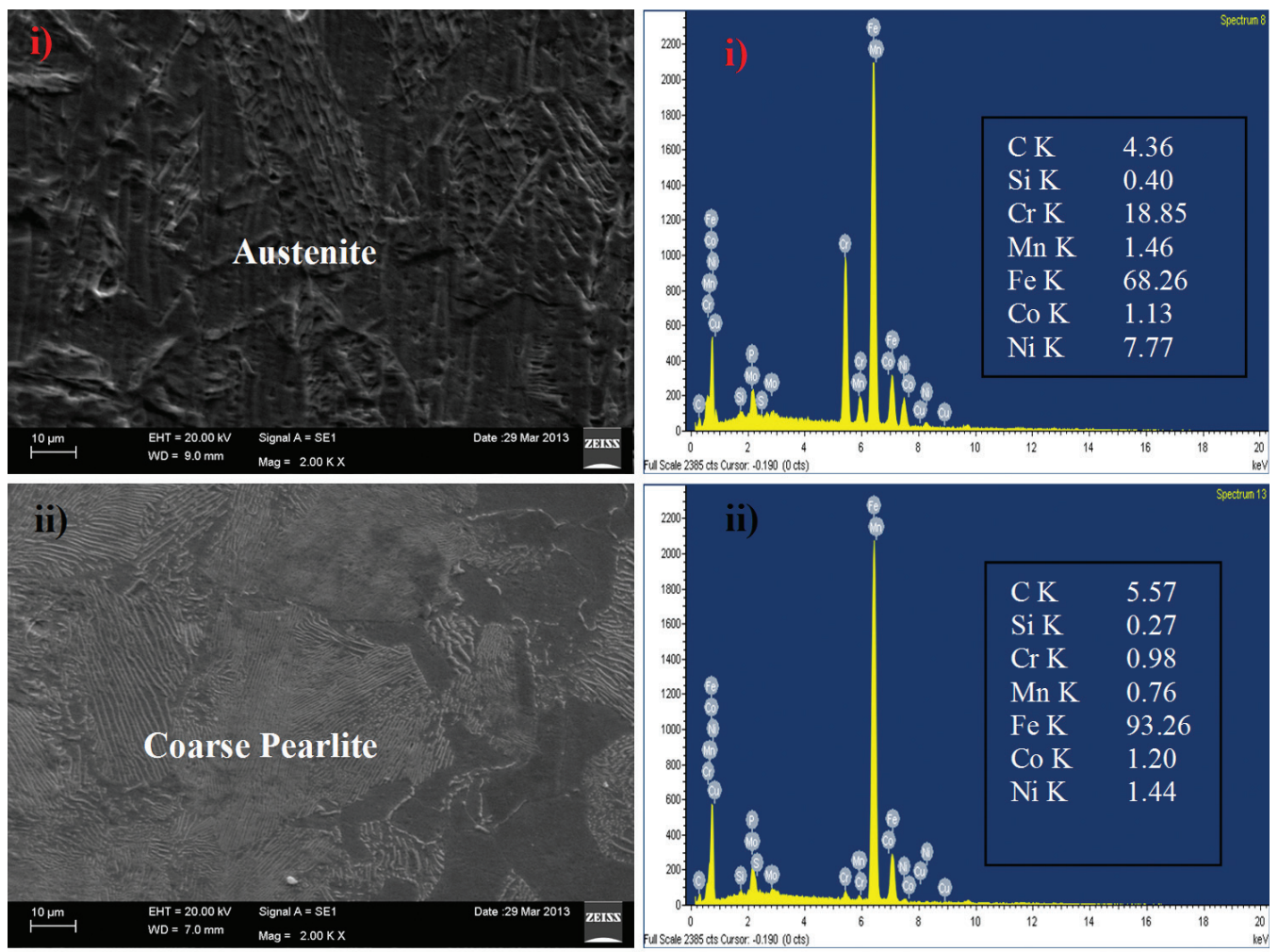

(a)

Figure 7. a) SEM/EDAX analysis on (i) Parent Metal AISI 304L (ii) Parent metal - AISI 4340, b) SEM/EDAX analysis on the zones of the CCGTA weldments employing ER309L (i) HAZ of AISI 304L (ii) Weld near AISI 304L fusion line (Z1)(iii) Weld near AISI 43404 fusion line(Z2) (iv) HAZ of AISI 4340. 

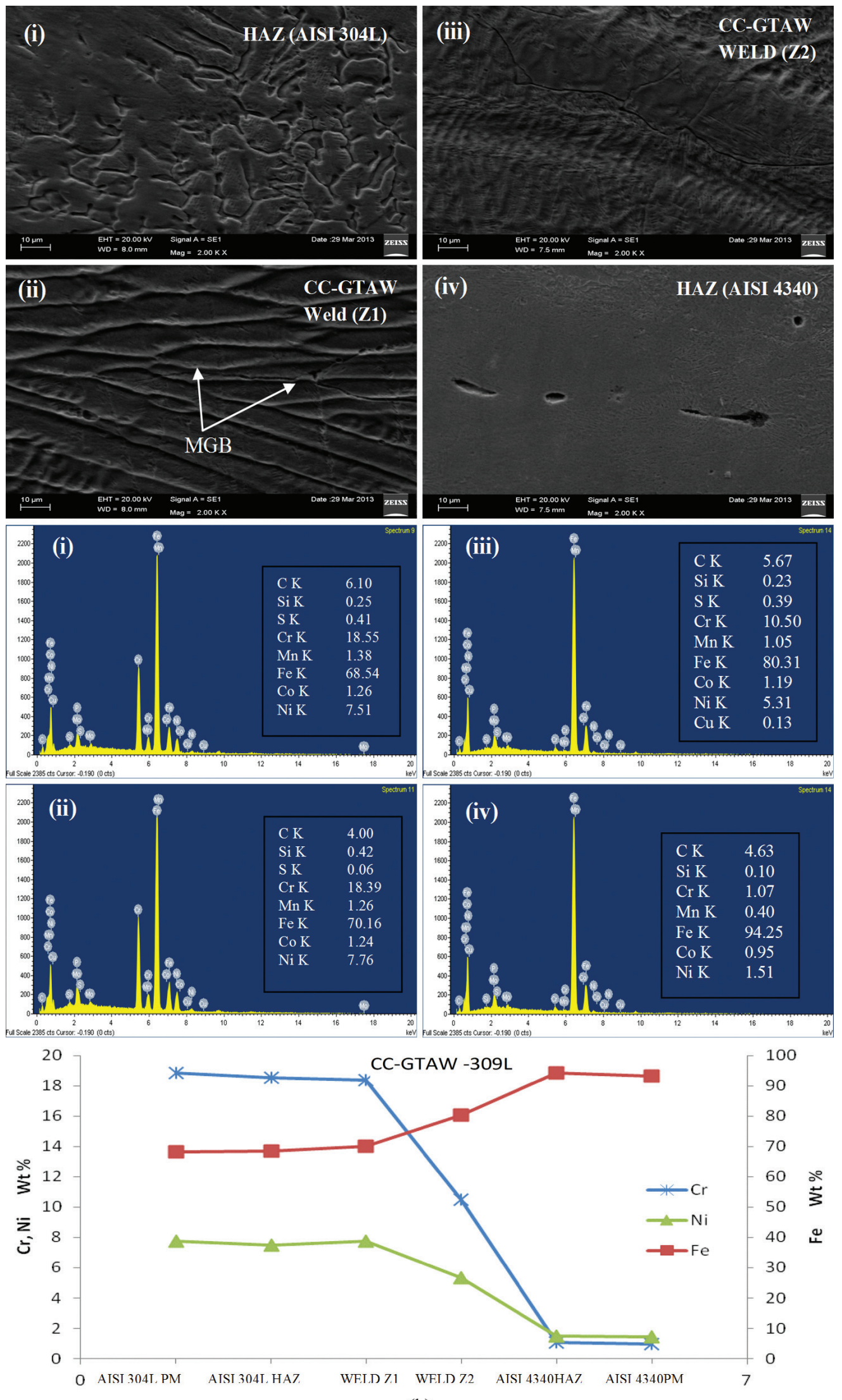

(b)

Figure 7 . Continued... 

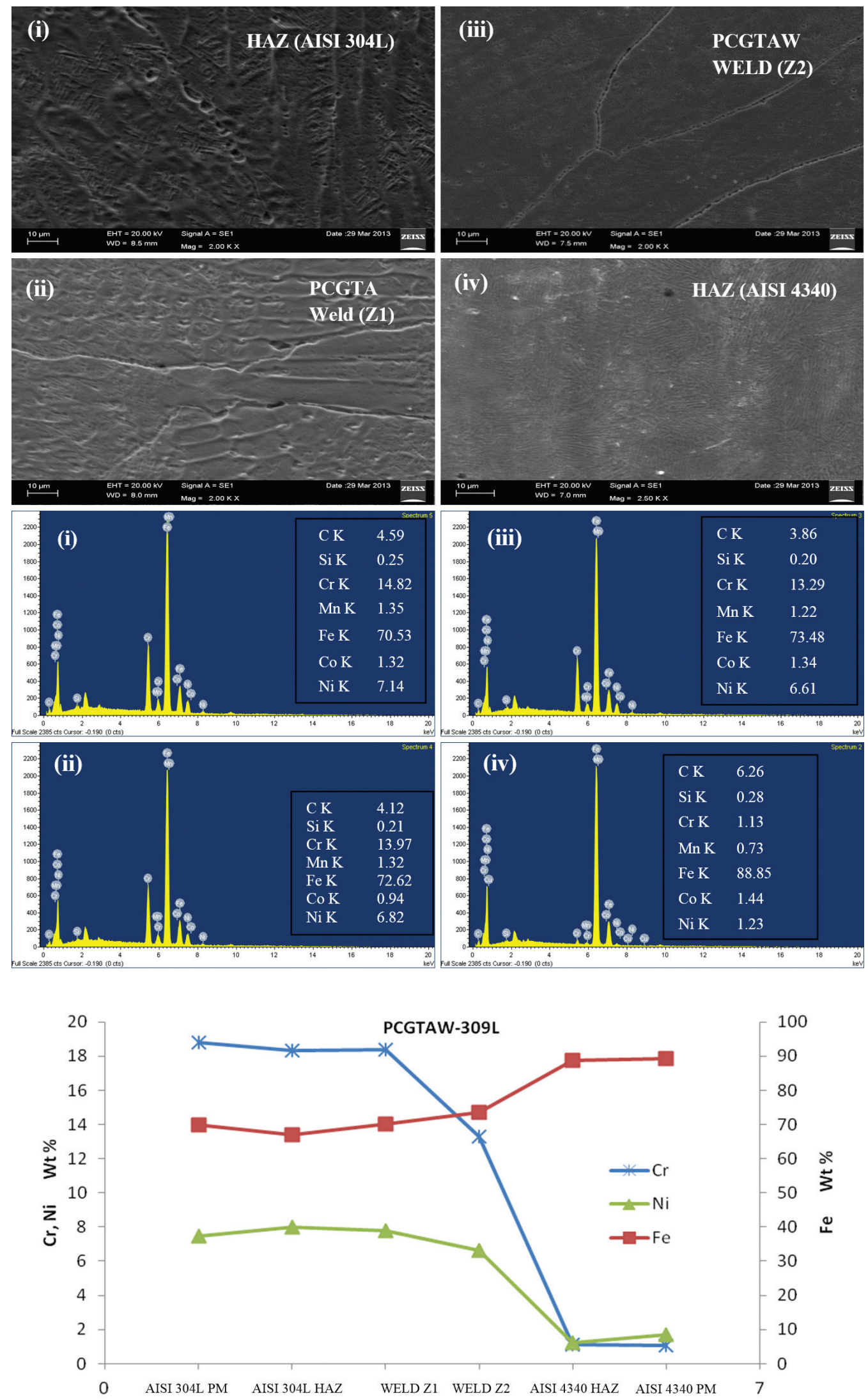

Figure 8. SEM/EDAX analysis on the zones of the PCGTA weldments employing ER309L (i) HAZ of AISI 304L (ii) weld near AISI 304Lfusion line (Z1) (iii) weld near fusion line of AISI 4340 (Z2) (iv) HAZ of AISI 4340. 

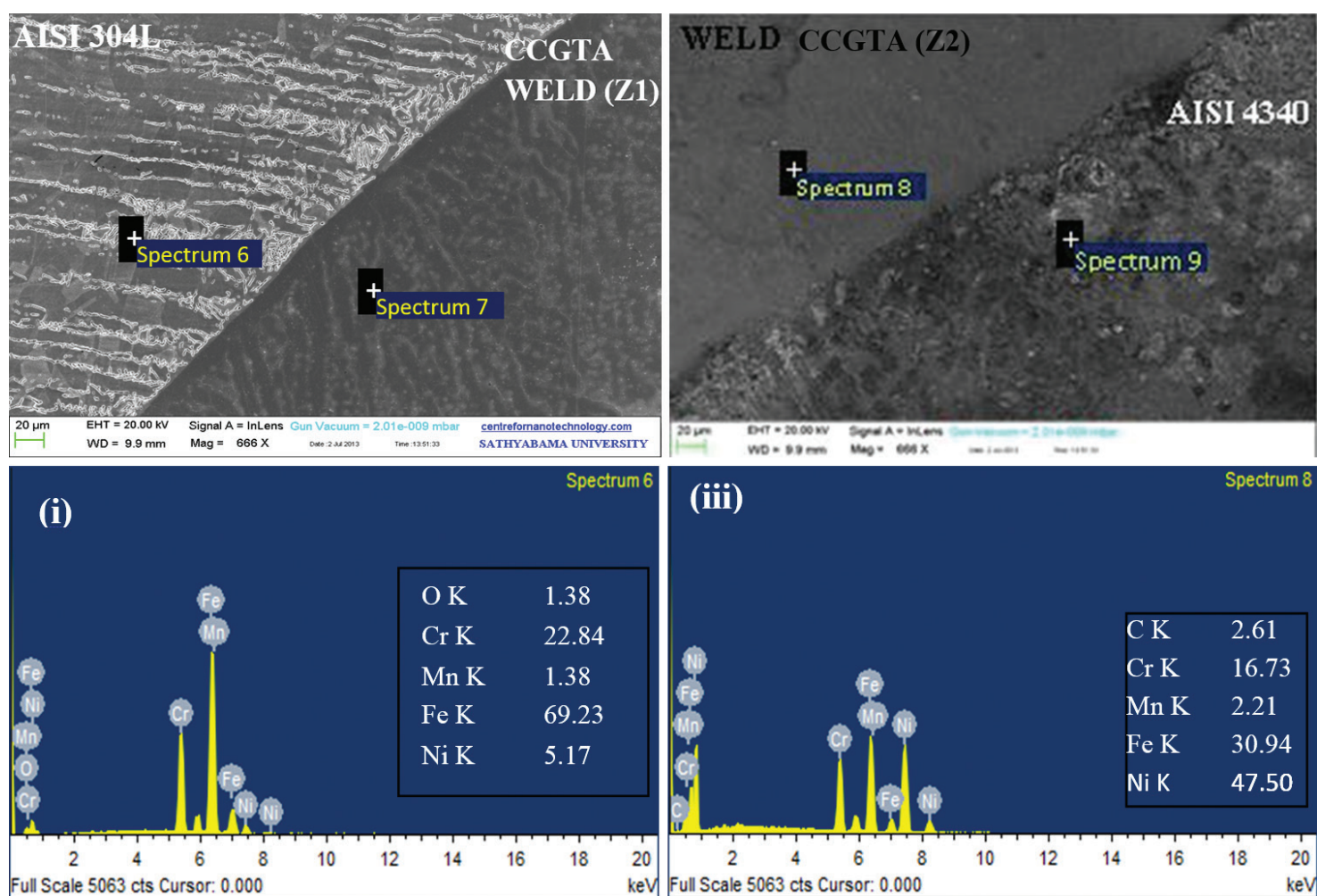

(iii)

Spectrum 8

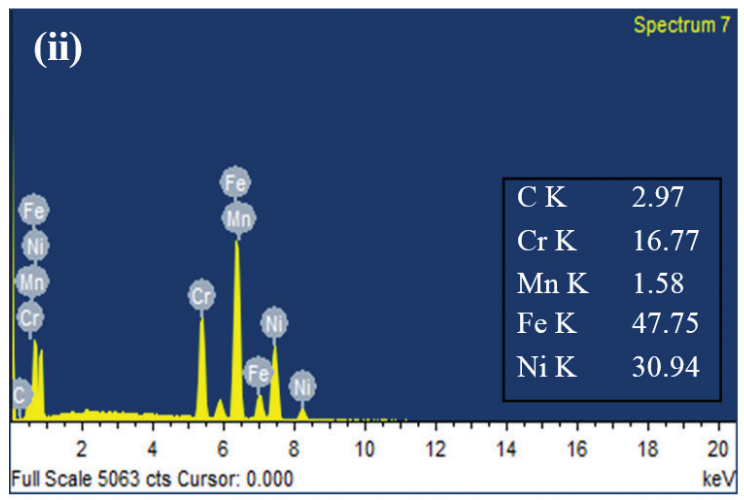

Full Scale 5063 cts Cursor: 0.000
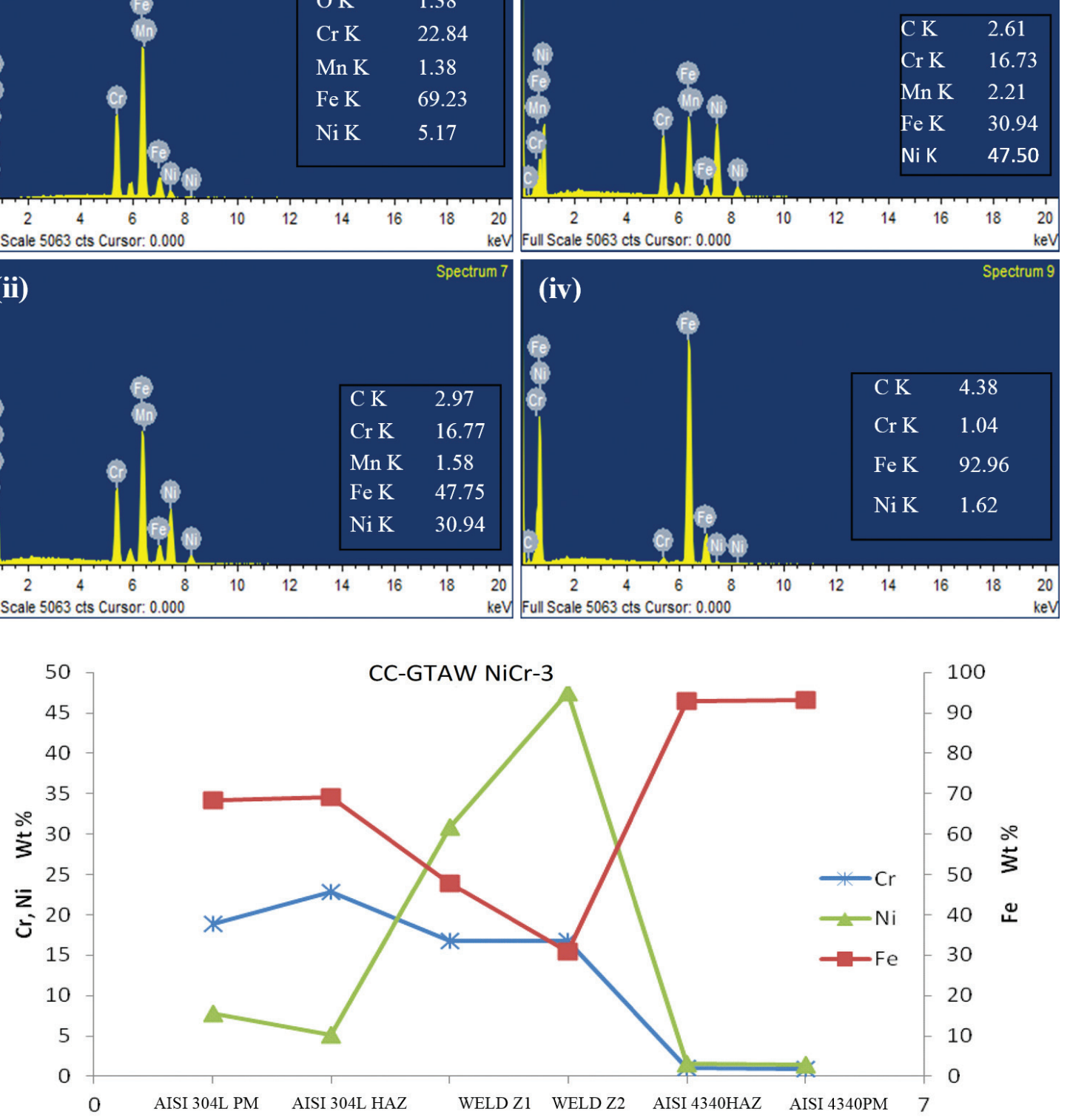

Figure 9. SEM/EDAX analysis on the zones of the CCGTA weldments employing ERNiCr-3 (i) HAZ of AISI 304L (ii) Weld Zone Near AISI304L (Z1) (iii) weld zone near AISI4340 (Z2) (iv) HAZ of AISI 4340. 

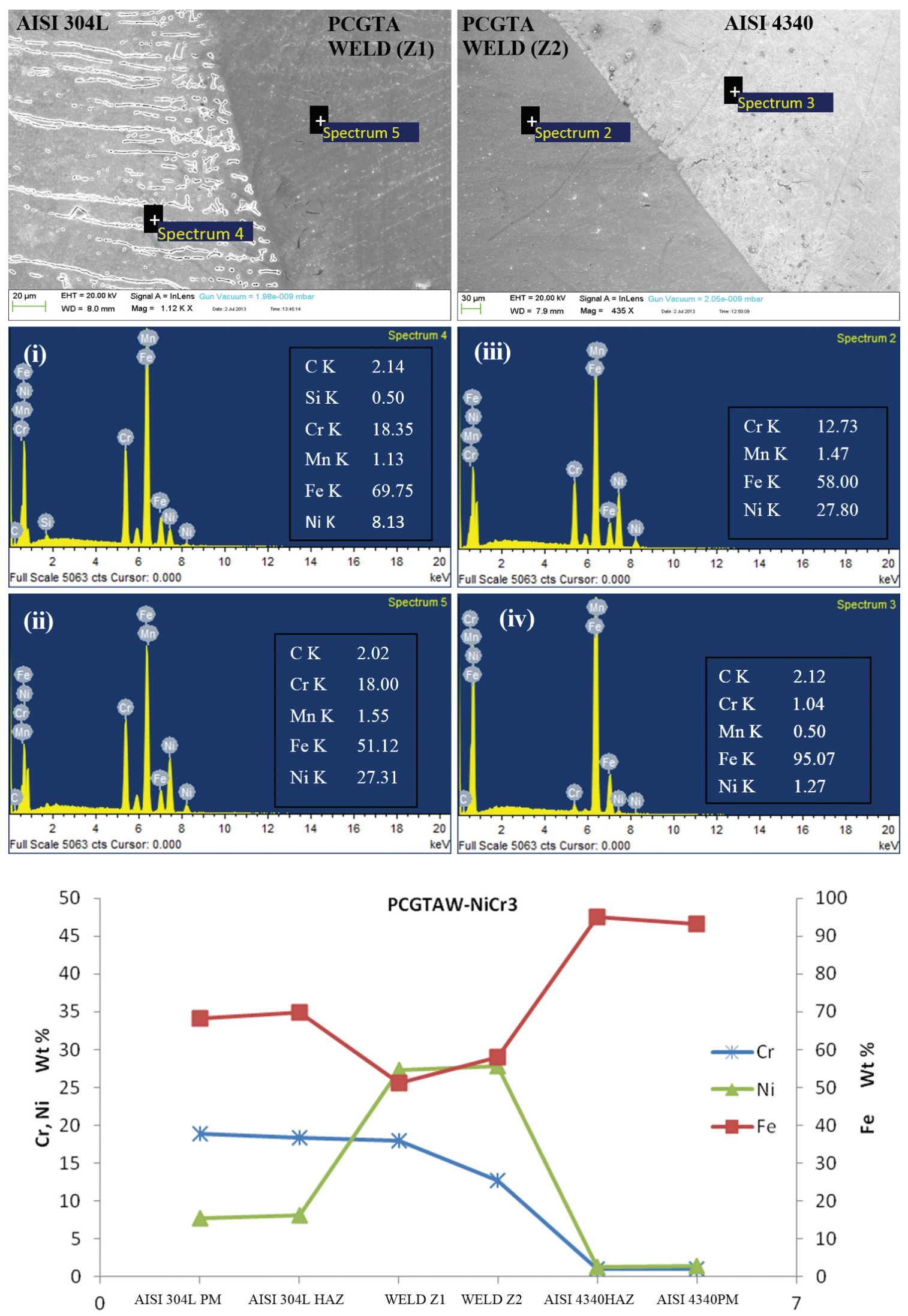

Figure 10. SEM/EDAX analysis on the various zones of the PCGTA weldments employing ERNiCr-3 (i) HAZ of AISI 304L (ii) WELD near AISI 304Lfusion line (Z1) (iii) weld near fusion line of AISI 4340 (Z2) (iv) HAZ of AISI 4340. 
indicated the formation of coarse dimples with macro voids/pores (Figure 14b).

On the other hand, the SEM fractographs featured the formation of fine dimples with micro-voids for the ERNiCr-3 CCGTA weldments Figure 14c; and a fibrous network with micro dimples was the classical feature observed in the SEM fractographs of the ERNiCr-3 PCGTA weldments shown in (Figure 14d).

\section{Discussions}

\subsection{Macro-structure for CCGTA VS PCGTA weld}

It is well indicated from (Figure 1) visual examination, NDT analysis followed by the macrostructure studies (Figure 2), that successful joints of AISI 4340 and AISI 304L could be obtained by both CCGTA and PCGTA welding techniques employing ERNiCr-3 and ER309L filler metals. The fusion was found to be proper on both the parent metals while employing these filler metals. As reported by Karunakaran, ${ }^{23}$ the PCGTA welds exhibit a narrow bead, and produce refined grains, which were also witnessed from the microstructure studies. Also, the sufficient preheating employed on the AISI 4340 side produced hard martensite; however, without cracking.

\subsection{Microstructure}

\subsubsection{CCGTA Vs PCGTA using ER309L filler wire}

Microstructure studies (Figures 3, 4) clearly inferred the formation of migrated grain boundaries (MGBs) at CCGTA and PCGTA weld zones and the solidification mode was found to be ferritic - austenitic due to high $\mathrm{Cr}_{\text {eq }} \backslash \mathrm{Ni}_{\text {eq }}$ ratio. As reported by Lippold, ${ }^{24}$ MGBs are most prevalent in the fully austenitic (A), Austenitic Ferritic (AF) and also in Ferritic Austenitic (FA) modes of solidification. In addition, the author has reported that MGBs are also formed on employing multi-pass welding. It was also reported that when the weld metal undergoes ferritic - austenitic (FA) solidification mode, the ferrite forms at the beginning of solidification. This was also in line with the Schaeffler diagram (Figure 11).

Formation of $\delta$ - ferrite in the vermicular form (skeletal ferrite) was observed at CCGTA welds (Figures 3b, c), which is due to the solidification of weld by moderate cooling rate, as reported by ${ }^{19}$. Whereas, $\delta$-ferrite fragments have been

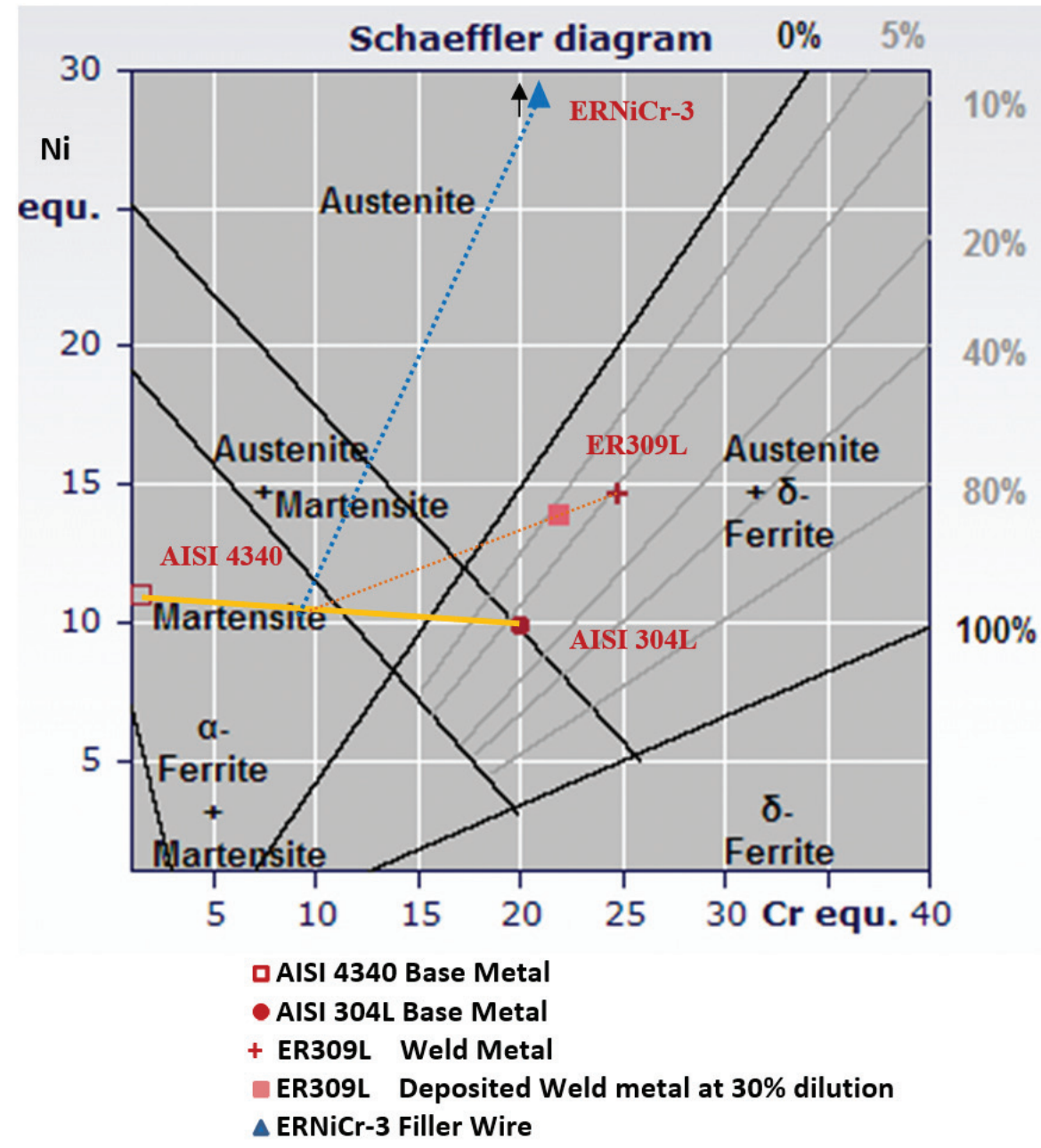

Figure 11. Schaeffler Diagram showing predicting mode of solidification for ER309L and ERNiCr-3 filler wires. 


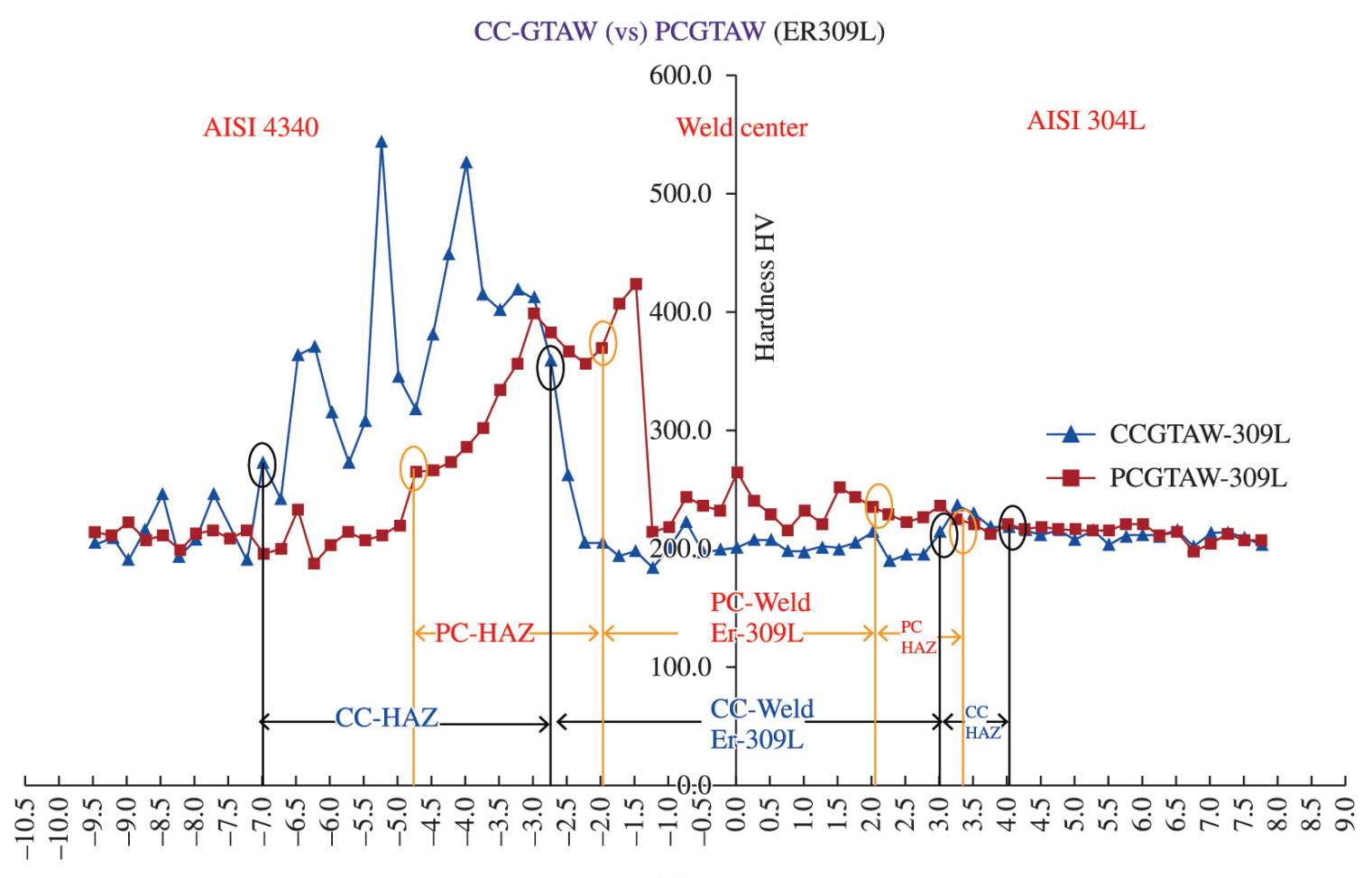

Distance

(a)

CCGTAW (vs) PCGTAW (ERNiCr-3)

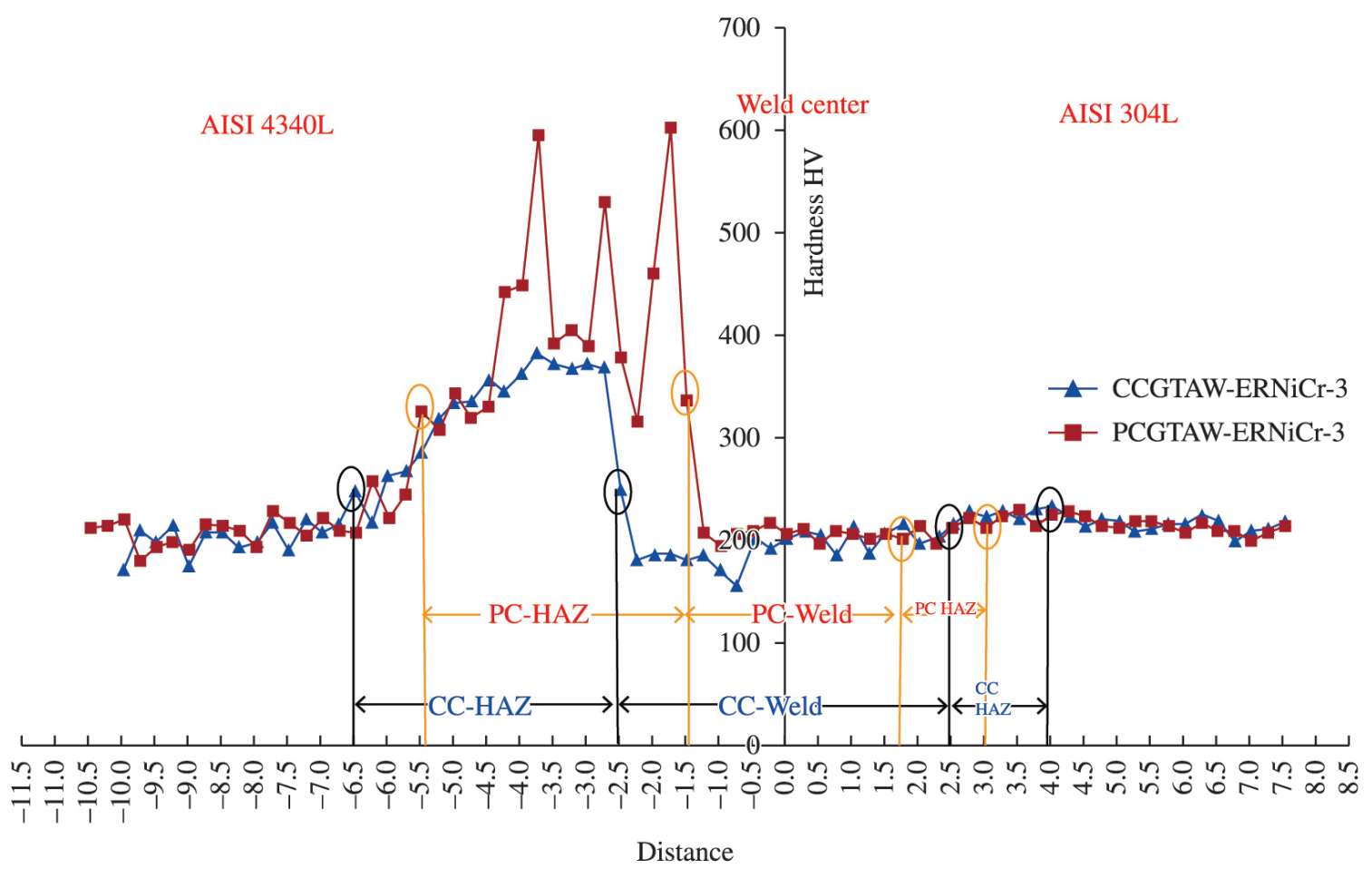

(b)

Figure 12. a) Hardness Profile of the dissimilar welds of AISI 4340 and AISI 304L with ER309L filler CCGTAW (vs.) PCGTAW b) Hardness Profile of the dissimilar welds of AISI 4340 and AISI 304L with ERNiCr-3 filler CCGTAW (vs.) PCGTAW. 

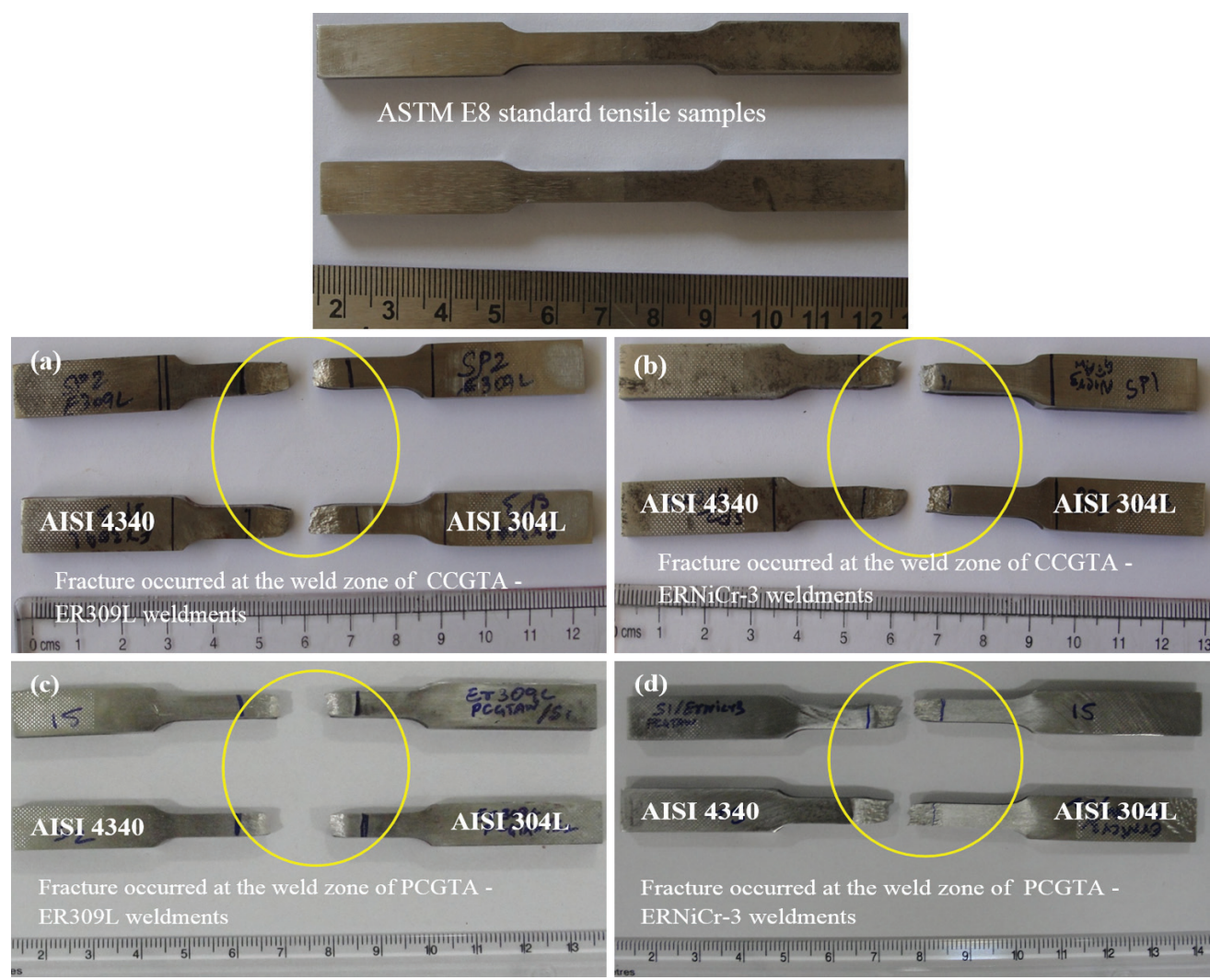

Fracture occurred at the weld zone of PCGTA -

ERNiCr-3 weldments

[T/

Figure 13. Fractured tensile samples of the dissimilar welds of AISI 4340 and AISI 304L a) CCGTA-ER309L b) PCGTA-ER309L c) CCGTAW-ERNiCr-3 d) PCGTA-ERNiCr-3.
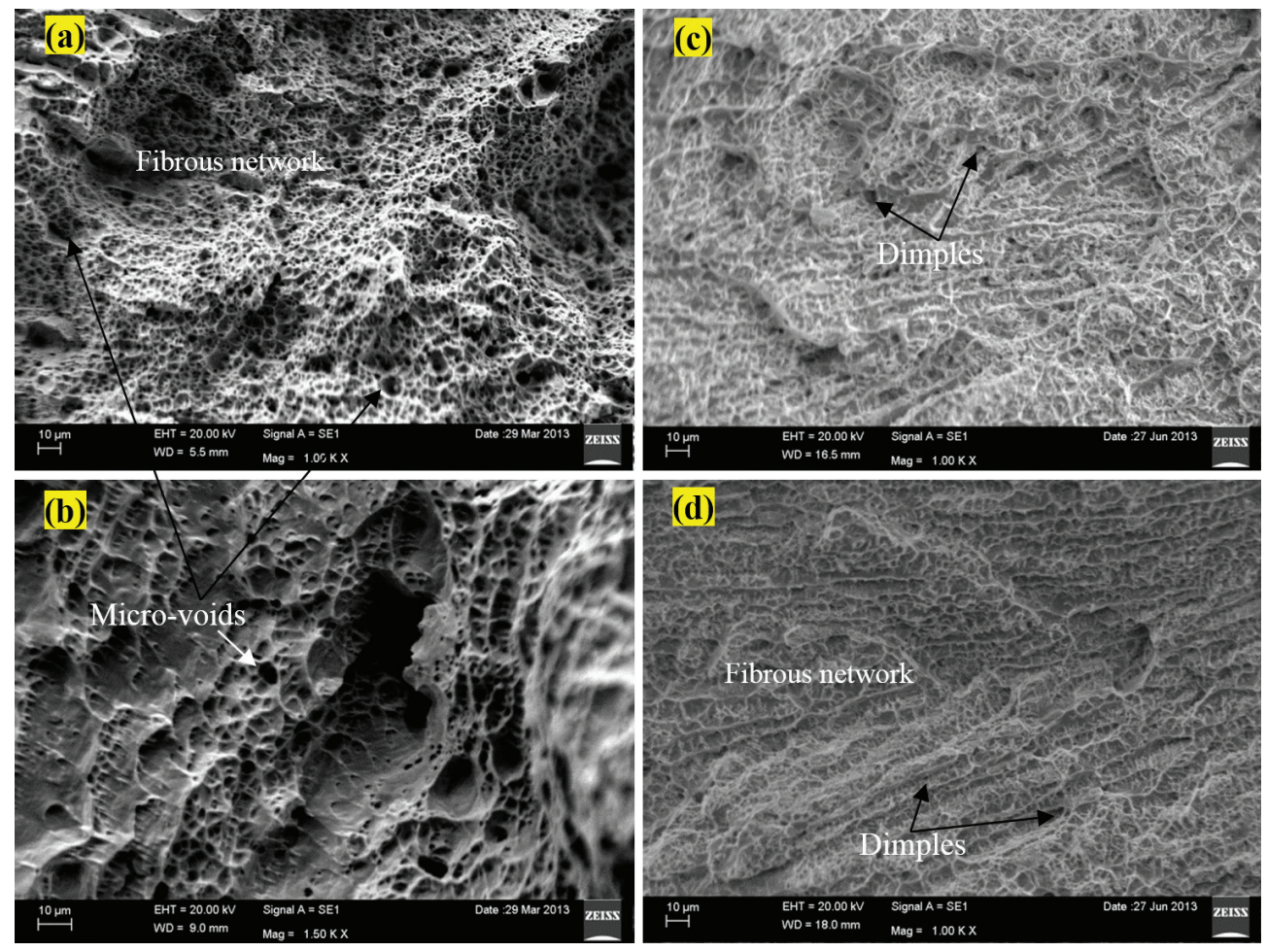

Figure 14. SEM Fractographs of dissimilar weldments obtained employing (a) CC-ER309L (b) PC-ER309L (c) CC-ERNiCr-3 (d) PC-ERNiCr-3. 
observed at the weld zone (Figure 4c) of PCGTA weldments which is due to arc pulsation. In addition, $\delta$ ferrite stringers are formed due to the greater amounts of ferrite stabilisers like $\mathrm{Cr}$ and $\mathrm{Mn}$ in the filler metal.

It was also examined in the microstructure studies that there was a formation of delta-ferrite stringers at the HAZ of AISI 304L for the CCGTA weldment. The heat produced during PCGTA welding will be dissipated immediately as compared to CCGTA welding and hence, a fragmentation of delta ferrite was observed at the HAZ of AISI 304L.Also, higher heat cycles are required to get the austenite to ferrite transformation. This is in agreement with the work reported by Lippold, ${ }^{24}$ that the degree of ferrite formation is usually low, since the austenite to ferrite transformation is relatively sluggish and the HAZ thermal cycle is normally quite rapid. The considerable migration of the ferrite stabilisers to the HAZ from the filler metal could be the reason for the formation of more amounts of delta ferrite stringers at the HAZ of AISI 304 L on the CCGTA weldments which is very less in the case of PCGTA weldments. It was also reported that the formation of ferrite stringers along HAZ grain boundaries would restrict grain growth and also, minimize the susceptibility to HAZ liquation cracking.

The microstructure at the HAZ of AISI 4340 steel consists of martensite phase originated from both the CCGTA and PCGTA welding processes. Since the temperature near the interface would reach the melting point of AISI 4340 steel followed by cooling from elevated temperatures, the AISI 4340 steel shall be subjected to a martensite transformation from austenite phase. Microstructure examination on the HAZ of AISI 4340 for ER309L CCGTA weldments witnessed the formation of martensite with few $\mathrm{M}_{23} \mathrm{C}_{6}$ carbides; whereas, the $\mathrm{HAZ}$ of AISI 304L revealed high amount of ferrites, which could be due to ferrite stabilisers $\left(\mathrm{Cr}_{\text {eq }} 24.76 \%\right)$. However, the microstructure of the parent metal AISI 4340 remained unchanged by exhibiting the coarse pearlite colonies.

\subsubsection{CCGTA Vs PCGTA using ERNiCr-3 filler wire}

Formation of migrated grain boundaries was observed at the weld zones of both weldments of ERNiCr-3 (Figures 5,6) similar to ER309L filler wire (Section 4.2.1). The mode of solidification was observed to be fully austenitic on employing ERNiCr-3 filler due to very less $\mathrm{Cr}_{\mathrm{eq}} \mid \mathrm{Ni}_{\mathrm{eq}}$ ratio and was also confirmed using Schaeffler diagram (Figure 11).

Formation of delta ferrite stringers was found in abundance at the HAZ of AISI 304L for the CCGTA weldments as compared to PCGTA weldments. The HAZ of AISI 4340 clearly demonstrated the formation of martensite, which could be due to the rapid cooling taken place at the weld interface and HAZ, similar to ER309L filler wire (Section 4.2.1).

CCGTA weld zone revealed the cellular dendrite in the weld center and columnar structure towards the fusion line of AISI 304L with the austenite phase, which is due to presence of austenite stabilisers ( $\mathrm{Ni}$ eq $75.83 \%$ ) in the filler wire.

In case of PCGTAW, the weld zone was observed having a cellular and equiaxed structure. The formation of cellular dendrite is the characteristic of nickel solidification with higher cooling rate, which normally enhances the mechanical property. Also, the cellular structure tends to grow as columnar structure towards the fusion line, which could be due to heat dissipation towards the base metal side.

In this study, all the weldments have shown the formation of MGBs. Hence, it is clear that the welds produced by both the welding techniques employing filler wires produced fully austenitic or austenitic- ferritic welds.

\subsection{SEM/EDS analysis}

\subsubsection{CCGTA Vs PCGTA using ER309L filler wire}

SEM/EDS analysis across the weldment [Base AISI 304L - HAZ (AISI 304L) -Weld zone(Z1) near AISI 4340 fusion line- Weld zone(Z2) near AISI 304L fusion line - HAZ (4340)- Base 4340] was carried out and the elements $\mathrm{Fe}, \mathrm{Ni}$ and $\mathrm{Cr}$ in the different zones are represented in Figures 7, 8. A meagre amount of Fe had migrated from AISI 4340 to weld zone in case of CCGTA weldments, whereas, negligible changes were observed on the PCGTA weldments. Similarly, Ni and $\mathrm{Cr}$ had diffused from weld zone to AISI 4340 side in both the welding processes.

The variation in the amounts of elements $\mathrm{Ni}, \mathrm{Cr}$ and $\mathrm{Fe}$ in the weld and HAZ could be due to the inter-dendrite segregation and other phases in the case of CCGTA welding process. This indicated that there was an enrichment of Fe, $\mathrm{Cr}$ and $\mathrm{Ni}$ at the weld interface of AISI 4340 side, which was also evident from the higher hardness values. Also, the percentage of carbon at the AISI 4340 side was more compared to the ER309L weld metal.

Diffusion of the elements, such as $\mathrm{Cr}$ and $\mathrm{Ni}$ from the weld zone to the HAZ of AISI 4340 resulted in the formation of carbides or secondary phases as evident from the microstructure analysis. This was also supported by the hardness profile, that maximum hardness was observed at the HAZ of AISI 4340, due to the formation of martensite and the presence of carbides. The EDS elemental analysis also concluded that the welds obtained from the CCGTA and PCGTA weldments employing ER309L produced a ferrite- austenitic structure, due to the higher amounts of $\mathrm{Cr}$ and $\mathrm{Ni}$.

\subsubsection{CCGTA Vs PCGTA using ERNiCr-3 filler wire}

$\mathrm{SEM} / \mathrm{EDS}$ for this discussion are represented in Figures 9, 10. Analysis on the PCGTA weldments employing ERNiCr-3 showed the presence of elements $\mathrm{Cr}$, Ni which were found to be lesser at the AISI 304L side, as compared to the weld zone. Since the weld zone was subjected to high temperature, $\mathrm{Ni}$ and Fe solutes diffused toward the weld zone. Unlike CCGTA welding process, there is no physical evidence of concentration of $\mathrm{Cr}$ and/or any other solutes to form the chromium carbides or complex phases in the PCGTA welds. The same was also inferred from the microstructure studies in terms of absence of the inter-dendrite segregation and formation of secondary phases in the welds. At the weld zone, the content of $\mathrm{Cr}$ reached to $15 \%$, and this shall be due to its large volatilizing loss during the welding process. From the EDS results, it was clear that the elements such as $\mathrm{Fe}, \mathrm{Cr}$ and $\mathrm{Ni}$ had a low degree of diffusion during PCGTA welding process. It is evident that these elements had not been given sufficient time for the diffusion to get across, due to controlled heat 
input. The HAZ of AISI 4340 witnessed the formation of Martensite $\left(\alpha+\mathrm{Fe}_{3} \mathrm{C}\right)$ in all the weldments, which has richer constituents of $\mathrm{Fe}$ and $\mathrm{C}$.

From the overall SEM/EDS analysis, it is palpable that the elemental migration was found to be lesser on employing PCGTA welding process as compared to CCGTA welding process. This could be due to pulsed current mode leading to higher cooling rate, producing refined microstructure. This process restricts the formation of secondary phases which tends to enhance the mechanical properties. Although the ERNiCr-3 filler wire contains $\mathrm{Nb}$ element, this was not revealed by the EDS analysis. From the available literature, it is observed that the addition of $\mathrm{Nb}$ in the weld could avoid the sensitization effect. Also, the presence of $\mathrm{Nb}$ contributed for resistance towards ductility dip cracking even though migrated grain boundaries were observed at the weld zones. It is also concluded from the welds obtained by the CCGTA and PCGTA, that the weldments produced using ERNiCr-3 resulted in fully austenitic welds due to the enriched amounts of $\mathrm{Ni}$ than $\mathrm{Cr}$.

\subsection{Micro-hardness}

\subsubsection{CCGTA Vs PCGTA using ER309L filler wire}

Plots of the micro-hardness data as a function of the position from the weld center line are presented in Figure 12a. The maximum hardness in the micro-hardness profile was observed in the HAZ of AISI 4340; therefore, it attributed for the strongest part of the joint. The greater hardness at the HAZ of AISI 4340 is due to the formation of martensite and the presence of secondary phases as observed in microstructure Figures 3, 4.

The weld zones of all the weldments exhibited lower magnitudes of hardness and attributed for weakest part of the joints. Formation of cellular dendritic structure at the PCGTA weld zone contributed for higher hardness as compared to the CCGTA weld zone of ER309L weldments.

As observed from the hardness plots, the HAZ of AISI 4340 had the range of hardness values between 300 and $550 \mathrm{HV}$. The microstructure of the CCGTA and PCGTA weldments was observed to have typical structures, including the precipitation of carbides and/or secondary phases. The fracture locations of the transverse tensile specimens were observed at the weld zone which clearly inferred that this zone is the weakest part and contributed for the lowest hardness as compared to other zones in the micro-hardness profile. The marginal increase in hardness at the weld near the interface of AISI 4340 may be due to the enrichment of Carbon, by elemental migration which is also evident from the micrographs. Conversely, the variations of hardness at the weld interface of AISI 304L side is negligible, and this could be due to the matching of austenite filler wire (ER309L) with parent metal.

\subsubsection{CCGTA Vs PCGTA using ERNiCr-3 filler wire}

Hardness profile (Figure 12b) clearly showed a similar trend, as discussed in previous section (4.4.1). Interestingly, the maximum hardness values were obtained at the HAZ of AISI 4340 for both the weldments. However, PCGTA weldments exhibited marginally higher hardness values compared to CCGTA weldments. It is evident from the micrographs that fully austenitic welds could be produced on employing Ni rich filler wire. Since the rate of cooling is faster in PCGTA compared to CCGTA welding technique, a hard martensitic structure with the presence of finer carbides was observed at the HAZ of AISI 4340 as observed in microstructure Figures 5-6.

Further, the migration of elements like $\mathrm{Ni}$ and $\mathrm{Cr}$ from weld zone to HAZ of AISI 4340 side was due to variation in the concentration gradient, which could also have enhanced the hardness. The variations in the hardness values shall be attributed to the differences in thermal conductivities. The higher thermal conductivity of AISI 4340 steel normally permits a rapid dissipation of the heat through the sample, while AISI 304L arrests the dissipation of heat because of lower thermal conductivity. As a result of this, a lower hardness is usually expected at the AISI 304L side, which is well in agreement with the findings of Özdemir et al. ${ }^{15}$.

\subsection{Tensile test}

Tensile properties of the dissimilar weldments obtained from CCGTA and PCGTA welding processes employing the filler wires is represented in Table 3 . It is obvious that PCGTA weldments offer better tensile properties in terms of strength as compared to the CCGTA weldments. This could be attributed to the absence of inter-dendritic segregation due to the controlled heat input developed during PCGTA welding process, as reported by Mohandas et al. ${ }^{17}$. However, while comparing the tensile properties in terms of the filler metals, both CCGTA and PCGTA weldments employing ERNiCr-3 showed satisfactory tensile properties as compared to ER309L weldments. This can be attributed to the presence of enriched amounts of $\mathrm{Ni}, \mathrm{Cr}$ and $\mathrm{Nb}$ present in the filler metal that could have probably formed the intermetallic compounds and contributed for greater strengths.

Tensile failures occurred at the weld zone in all the weldments. As discussed in the earlier sections, the hardness trend had clearly represented the lower hardness values at the weld zone for all the weldments. Lower the hardness, lesser would be the strength of the material. The presence of martensite at the HAZ of AISI 4340 and the presence of vermicular ferrite and/or $\delta$-ferrite stringers in $\gamma$ - phase at the HAZ of AISI 304L contributed for better strength. Hence, the tensile failures could not have occurred at these zones. Another supporting fact towards the discussion is that the MGBs observed at the weld zones in case of all the weldments deteriorated the tensile properties and caused the failure to occur at this zone. SEM fractographs revealed the presence of dimples; micro-voids indicated that the weldments underwent fracture by ductile mode. Voids were observed more in the weldments employing ER309L as compared to ERNiCr-3 shown in Figures 14a, b. It is known, that the voids which are termed as the basic entities of ductile fracture, nucleate heterogeneously at sites, where compatibility of deformation is difficult. The preferred sites for void formation are possibly these secondary phase elements. The appearance of the fractured surface consisted of different types of dimples, and the larger ones may have resulted from chromium carbide precipitates. ${ }^{15}$ 
Table 3. Cumulative Mechanical Properties of the dissimilar weldments.

\begin{tabular}{|c|c|c|c|c|c|c|c|}
\hline \multirow[b]{2}{*}{$\begin{array}{c}\text { Trial } \\
\text { No }\end{array}$} & \multirow[b]{2}{*}{$\begin{array}{l}\text { Welding } \\
\text { Process }\end{array}$} & \multicolumn{3}{|c|}{ Tensile Properties } & \multicolumn{3}{|c|}{ Micro-Hardness Properties } \\
\hline & & $\begin{array}{c}\text { Average UTS } \\
\text { (Mpa) }\end{array}$ & $\begin{array}{c}\% \text { of } \\
\text { Elongation }\end{array}$ & Failure in & $\begin{array}{c}\text { Average } \\
\text { hardness in } \\
\text { weld zone }(\mathrm{HV})\end{array}$ & $\begin{array}{c}\text { Average } \\
\text { hardness in } \\
\text { HAZ (HV) } \\
4340\end{array}$ & $\begin{array}{c}\text { Average } \\
\text { hardness in } \\
\text { HAZ (HV) } \\
\text { 304L }\end{array}$ \\
\hline 1 & $\begin{array}{c}\text { CCGTAW } \\
\text { ER309L }\end{array}$ & 562.66 & 28.0 & WELD & 203 & 373 & 226 \\
\hline 2 & $\begin{array}{c}\text { PCGTAW } \\
\text { ER309L }\end{array}$ & 602.66 & 27.2 & WELD & 258 & 326 & 228 \\
\hline 3 & $\begin{array}{c}\text { CCGTA } \\
\text { ERNiCr-3 }\end{array}$ & 611.5 & 27.1 & WELD & 194 & 339 & 228 \\
\hline 4 & $\begin{array}{l}\text { PCGTAW } \\
\text { ERNiCr-3 }\end{array}$ & 665.33 & 26.0 & WELD & 207 & 418 & 217 \\
\hline
\end{tabular}

\section{Conclusions}

Based on the results of the above studies, the following conclusions could be drawn and are reported as follows:

a) Sound welds of austenitic stainless steel (AISI 304L) and Aeronautical Steel (AISI 4340) could be obtained from both CCGTA and PCGTA welding process using ER309L and ERNiCr-3 filler wires.

b) The study opined that continuous current and pulsed current has significant role in altering the metallurgical and mechanical properties of these dissimilar weldments.

c) Narrow weld beads could be produced on employing PCGTA welding, which in turn lowers the width of HAZ.

d) Welds made by CCGTAW with both filler wires showed relatively coarser microstructure, with occurrences of secondary phase(s) at the weld interface of AISI 4340 side. Also, the weld zone consists of columnar dendrites, which are due to continuous current and slow dissipation of heat.

e) The controlled/reduced heat input and solidification associated with pulsed current mode has resulted in the elimination of precipitation of secondary phase(s) and reduced grain coarsening in HAZ of AISI 4340, in both filler wires.

f) Refined microstructure in the weldments, heterogeneous nucleation and reduced elemental migration are all the typical advantages accrued on employing PCGTA welding. The results were depicted in terms of equiaxed / fine cellular dendritic structure in the ERNiCr-3 weldment and $\delta$ ferrite fragmentation in case of ER309L weldment, which led to the improved tensile strength.

g) Welding of these dissimilar metals resulted in the formation of different micro-structure zones, which is due to the differences existing in the thermal gradients, chemical composition. The various zones observed at the weldments include martensite, vermicular ferrite, ferrite stringers and equi-axed cellular/columnar dendrite.

h) The ferrite stabilisers in the ER309L filler wire resulted in the primary ferrite solidification in weldment, which resulted in the formation of $\delta$ ferrites assisting in the elimination of solidification cracking and micro fissuring.

i) Microstructure examination confirmed the absence of sensitization effect on employing both ER309L and ERNiCr-3 fillers. However, the presence of $\mathrm{Nb}$ in the ERNiCr-3 imparted additional strength to the welds, which in turn accounted for better tensile properties.

j) Migrated grain boundaries at the weld zone could have resulted due to the multi-pass welding. Also, MGBs are prevalent in the weld zones on employing ER309L and ERNiCr-3, which contribute for either fully austenitic or ferritic - austenitic welds.

The migration of elements is totally minimized on employing PCGTA welding process. The higher values of tensile strength observed in the PCGTA weldments can be attributed to the absence of complex phases at the interface as well as grain refinement.

k) Carbon denuded soft zone is not observed at the HAZ of AISI 4340 in these weldments, which is also confirmed from the micro-hardness survey.

1) Pulsed current mode resulted in better tensile properties compared to the continuous current. Further, the PCGTA weldments employing ERNiCr-3 had proven to offer better strength as compared to all other weldments.

m) Based on the present studies, it is highly recommended to employ PCGTA welding using ERNiCr-3 owing to the several advantages accrued, and can be possibly adopted in the industries demanding these bimetallic joints.

\section{Acknowledgements}

The authors sincerely thank Aeronautical Research and Development Board (AR\&DB) Government of India (GOI), for providing the financial aid towards this research work. Also, the authors convey their sincere thanks to Department of Science and Technology -FIST for establishing the Instron facility in VIT University, Vellore. The authors gratefully acknowledge the support of Mr. Natarajan, Delta Wear Tech Engineers, Chennai for providing necessary consumables. 


\section{References}

1. Gonser BW. Modern materials- advances in development and applications. New York: Academic Press; 1964.

2. Mishler HW, Monroe RE and Rieppel PJ. Welding of highstrength steels for aircraft and missile applications. Defence Metals Information Center Ohio; 1959.

3. Viswanathan R and Bakker W. Materials for Ultra supercritical Coal Power Plants-Boiler Materials: Part 1. Journal of Materials Engineering and Performance. 2001; 10(1):81-95. http://dx.doi.org/10.1361/105994901770345394.

4. Baddoo NR. Stainless steel in construction: A review of research, applications, challenges and opportunities. Journal of Constructional Steel Research. 2008; 64(11):1199-06. http:// dx.doi.org/10.1016/j.jcsr.2008.07.011.

5. Sheila MC and Milton SFL. Laser beam welding tempered 300M ultrahigh mechanical strength steel. Journal of the Brazilian Society of Mechanical Sciences and Engineering. 2012; 34:18-23.

6. Roshanghias A, Barzegari M, Kokabi AH and Madaah Hosseini MHR. Welding Characteristics of Ultrahigh Strength Steel in Annealed and Quench-Tempered Conditions. Journal of Materials Engineering and Performance. 2010; 19(7):963-969. http://dx.doi.org/10.1007/s11665-009-9586-4.

7. Hasçalik A, Ünal E and Özdemir N. Fatigue behaviour of AISI 304 steel to AISI 4340 steel welded by friction welding. Journal of Materials Science. 2006; 41(11):3233-3239. http://dx.doi. org/10.1007/s10853-005-5478-7.

8. Arivazhagan N, Surendra S, Prakash S and Reddy GM. Investigation on AISI 304 austenitic stainless steel to AISI 4140 low alloy steel dissimilar joints by gas tungsten arc, electron beam and friction welding. Materials \& Design. 2011; 32(5):3036-3050. http://dx.doi.org/10.1016/j. matdes.2011.01.037.

9. Bhaduri AK, Venkadesan S, Rodriguez P and Mukunda PG. Transition metal joints for steam generators -An overview. International Journal of Pressure Vessels and Piping. 1994; 58(3):251-265. http://dx.doi.org/10.1016/03080161(94)90061-2.

10. Naffakh H, Shamanian M and Ashrafizadeh F. Weldability in dissimilar welds between Type 310 austenitic stainless steel and Alloy 657. Journal of Materials Science. 2008; 43(15):53005304. http://dx.doi.org/10.1007/s10853-008-2761-4.

11. Nissley NE and Lippold JC. Ductility-dip cracking susceptibility of nickel-based weld metals- Part 2. Welding Journal. 2009; 88:31-40.

12. Gooch TG and Honeycombe J. Welding variables and micro fissuring in austenitic stainless steel weld metal. Welding Research Supplement. 1980:233s-241s.

13. Lalam SV, Reddy GM, Mohandas T, Kamaraj M and Murty BS. Continuous drive friction welding of Inconel
718 and EN24 dissimilar metal combination. Materials Science and Technology. 2009; 25(7):851-861. http://dx.doi. org/10.1179/174328408X369384.

14. Kearns WH, editor. Welding handbook: metals and their weldability. 7th ed. Miami: American Welding Society; 1982. v. 4.

15. Özdemir N, Sarsılmaz F and Hasçalık A. Effect of rotational speed on the interface properties of friction-welded AISI 304L to 4340 steel. Materials \& Design. 2007; 28(1):301-307. http:// dx.doi.org/10.1016/j.matdes.2005.06.011.

16. Sundaresan S, Janaki Ram GD and Madhusudhan Reddy G. Microstructural refinement of weld fusion zones in $\alpha-\beta$ titanium alloys using pulsed current welding. Materials Science and Engineering A. 1999; 262(1-2):88-00. http://dx.doi. org/10.1016/S0921-5093(98)01010-7.

17. Mohandas T and Madhusudhan Reddy G. A comparison of continuous and pulse current gas tungsten arc welds of an ultra high strength steel. Journal of Materials Processing Technology. 1997; 69(1-3):222-226. http://dx.doi.org/10.1016/ S0924-0136(97)00022-8.

18. Sireesha M, Albert SK, Shankar V and Sundaresan S. A comparative evaluation of welding consumables for dissimilar welds between 316LN austenitic stainless steel and Alloy 800 . Journal of Nuclear Materials. 2000; 279(1):65-76. http:// dx.doi.org/10.1016/S0022-3115(99)00275-5.

19. Hajiannia I, Shamanian M and Kasiri M. Microstructure and mechanical properties of AISI 347 stainless steel/A335 low alloy steel dissimilar joint produced by gas tungsten arc welding. Materials \& Design. 2013; 50:566-573. http://dx.doi. org/10.1016/j.matdes.2013.03.029.

20. Madhusudhan Reddy G, Mohandas T and Tagore GRN. Weldability studies of high-strength low-alloy steel using austenitic fillers. Journal of Materials Processing Technology. 1995; 49(1-2):213-228. http://dx.doi.org/10.1016/09240136(94)01317-T.

21. American Society for Testing and Materials-ASTM. E8/E8M - 13a: Standard test methods for tension testing of metallic materials. West Conshohocken; 2013. v. 3.01.

22. Naffakh H, Shamanian M and Ashrafizadeh F. Microstructural evolutions in dissimilar welds between AISI 310 austenitic stainless steel and Inconel 657. Journal of Materials Science. 2010; 45(10):2564-2573. http://dx.doi.org/10.1007/s10853010-4227-8.

23. Karunakaran N. Effect of pulsed current on temperature distribution, weld bead profiles and characteristics of GTA welded stainless steel joints. International Journal of Engineering \&Technology. 2012; 2:1908-1916.

24. Lippold JC and Koteki DJ. Welding metallurgy and weldability of stainless steels. 2nd ed. New Jersey: John Wiley \& Sons; 2005 . 